\title{
Effect of water absorption on Mode I interlaminar fracture toughness of flax/basalt reinforced vinyl ester hybrid composites
}

\author{
F.A. Almansour ${ }^{\text {a }}{ }^{*}$, H.N. Dhakal ${ }^{a}$ and Z.Y. Zhang ${ }^{a}$ \\ ${ }^{a}$ Advanced Polymer and Composites (APC) Research Group, School of Engineering, University \\ of Portsmouth, Portsmouth, Hampshire, PO1 3DJ, United Kingdom.
}

\begin{abstract}
In this study, the influence of water absorption on the Mode I interlaminar fracture toughness of flax and basalt fibre reinforced vinyl ester hybrid composites is presented. Three types of composite laminates namely, flax fibre reinforced vinyl ester (FVE), flax fibre hybridised basalt unstitched (FBVEu) and flax hybridised basalt stitched (FBVEs), fabricated by vacuum infusion technique are investigated. Double cantilever beam (DCB) tests were performed to evaluate the Mode I critical energy release rate $\left(\mathrm{G}_{\mathrm{IC}}\right)$ and the crack length (Rcurve) by using three different data reduction methods. It was found from the experimental results that the Mode I fracture toughness initiation and propagation of water immersed FVE composites were decreased by an average of $27 \%$ and $10 \%$ respectively, compared to the dry specimens, whereas the fracture toughness propagation of water immersed FBVEu and FBVEs composites were improved by approximately $15 \%$ and $17 \%$ compared to dry specimens. The fractured surface and delamination of different composites were evaluated by using scanning electron microscopy (SEM) and x-ray computed micro-tomography $(\mu \mathrm{CT})$. The results showed that basalt fibre hybridisation has positive effects on durability and the moisture resistance of natural fibre composites.
\end{abstract}

Keywords: Natural fibre reinforced composites (NFRCs), Interlaminar fracture toughness, Mode I, Delamination.

\footnotetext{
* Corresponding author. Tel.: +44 (0) 2392842586.

E-mail address: fahad.almansour@port.ac.uk (F.A. Almansour).
} 


\section{Introduction}

Recent developments in natural fibre reinforced composites (NFRCs) have led to renewed interest in semi-structural and structural applications especially in the automotive and construction sectors as an alternative material to synthetic fibre composites. The reasons for this shift to the use of natural fibre composites are due to increased global awareness and new environmental legislation requiring manufacturers to adapt sustainable materials (1) Furthermore, due to increased consumer awareness and the need for lightweight components in order to reduce overall $\mathrm{CO}_{2}$ emissions, the automotive industry is leading the way in using natural fibre composites and bio-composites. The hybrid composites developed by using flax and basalt fibres not only provide weight savings but also offer more environmentally friendly composites which can further be applied in the marine and construction industries (2).

In a recent extensive review relating to the use of natural plant fibres for structural applications, it has been highlighted that there have been several research works conducted focusing on the development of NFRCs for structural applications (3). The review concluded that natural (bast) fibres have superior mechanical properties due to their chemical and structural composition which contains high cellulose and aspect ratio with low micro-fibril angles. Thus, natural fibres can be most appropriate to be used as reinforcements in the composite industries as these natural fibres provide the best potential integration of light weight and low cost, with high specific strength and modulus (4). However, NFRCs have lowdurability and inherently absorb high moisture which can reduce their properties and thus affect the long-term performance. For example, increased moisture content in natural fibres causes swelling and alters their dimensions because of the poor adhesion/compatibility between the hydrophobic matrix and hydrophilic natural fibres $(5,6)$. Previous studies have reported the effect of water absorption on the properties of NFRCs, such as hemp (7), jute (8) and flax (9). These reports have shown that increased moisture uptake of natural bast fibres is due to high cellulose and voids content, and the mechanical properties such as tensile and flexural strength would be significantly lowered as a consequence of weak interfacial adhesion between fibre and matrix.

Delamination is one of the most prevalent failure mechanisms in composite laminates. It usually occurs due to dynamic loadings, such as low-velocity impact when the structure is subjected to cyclic or static loading conditions (10). Sufficient ability to absorb fracture energy is an important requirement for structure design, which is dependent on the fibre and matrix properties. Because of this, the use of natural fibres in the form of non-woven mats and short 
fibres is limited in non-structural applications (11). However, in order to obtain high performance composites in terms of stiffness and strength, it is important to use long continuous unidirectional fibres or woven non-crimp fabrics (12).

Many research works have been carried out on the hybrid system in composites materials (13-18) which contain two or more different types of natural and synthetic fibres in a similar matrix. Due to their unique attributes of achieving tailored material performance, hybrid composite systems have recently received significant attention. Common reinforcements used in hybrid systems include carbon and glass fibres as well as other nanoparticles. In recent years, basalt fibre has been one of the popular reinforcements used to hybridise natural fibre composites. The main reason for this include, but are not limited to basalt fibre being originated from nature and has less environmental damage compared to non-renewable reinforcements such as carbon and glass fibres. In addition, this fibre has high chemical stability as well as resistance to high temperature, and it is produced from commonly occurring rock (19). Fiore et al. (14) showed that the addition of two external layers of basalt fibre enhanced the mechanical properties of flexural and tensile compared to glass fibre reinforced composites without hybridisation.

From the studies reported in the literature, very limited work has been documented in the analysis of fracture toughness behaviour of natural fibre composites. In addition, there are no reported works on the effect of water absorption on the fracture toughness of NFRCs. Also, very few studies have been undertaken to improve the fracture toughness of NFRCs by chemical treatment $(20,21)$ and fibre or matrix hybridisation (22-24). Li et al. (20) have conducted the fracture toughness test to investigate the effects of fibre surface treatment of sisal fibre reinforced vinyl ester composites. They found that the permanganate and silane treated systems improved the fracture toughness in comparison to the untreated systems with critical strain energy release rate $\left(\mathrm{G}_{\mathrm{IC}}\right)$ of $1682.2 \mathrm{~J} / \mathrm{m}^{2}$ to $1488.3 \mathrm{~J} / \mathrm{m}^{2}$ and $1158.7 \mathrm{~J} / \mathrm{m}^{2}$, respectively. However, Silva et al. (21) reported that the alkaline treatment contributed to lower the fracture toughness of the sisal fibre reinforced polyurethane composites. This behaviour was attributed as a result of improved interfacial adhesion between fibre and the matrix which affected debonding and fibre pull-out which reduced the fracture energy absorption. Hence, the use of thermoplastic matrix material such as polypropylene and polyurethane leads to a decrease of mechanical properties caused by a weak bond to natural fibres, and they also have lower mechanical properties compared to thermosets (12). Wong et al. (23), for example, noted that the interlaminar fracture toughness $\left(\mathrm{G}_{\mathrm{IC}}\right)$ of flax fibre reinforced hyperbranched polymers (HBP) with poly(L-lactic acid) (PLLA) was significantly increased when modified and blended 
together. Moreover, the toughness properties were improved due to better wetting of the fibres by these matrices. From a review of this literature, it can be concluded that of central importance in using natural fibre composites in structural applications is the measurement of their fracture toughness behaviour.

Amongst the several textile methods of inserting through-thickness fibre reinforcements, stitching, knitting and weaving are the methods used to improve the interlaminar fracture toughness. It is likely that the most common of these techniques is stitching because of its versatility and convenience (25-27). By using stitching through-thickness reinforcement, the fracture toughness of the composites has been improved as a result of providing a more integrated composite structure (30). However, it has been observed in the previous studies that stitching can cause in-plain fibre damage and create resin-rich regions which can lead to a reduction of the flexural, compressive and tensile properties (30,31). Indeed, it is difficult to predict the influence of stitching on the in-plane mechanical properties owing to many factors, such as the type of the composite laminates, fabrication techniques and also the important parameters of stitching (stitch density, pattern, span, yarn diameter, type of thread) (32). More recent published work by Ravandi et al. (33) examined the effects of stitching throughthickness reinforcement using natural fibres on Mode I interlaminar fracture toughness of flax fibre/epoxy composites. It was found that the interlaminar fracture toughness of woven flax composites was significantly higher than glass fibre composites. Moreover, flax yarn stitches exhibited improved fracture toughness of the laminates compared to cotton thread stitches.

The work reported in this paper is aimed at characterising the Mode I interlaminar fracture toughness of flax fibre and flax/basalt reinforced vinyl ester composites. To the best of our knowledge, there are no reported works on the influence of water absorption relating to fracture toughness behaviour of flax fibre and basalt fibre hybridised composites. Herein, for the first time this report presents a detail investigation into the effects of water absorption behaviour and its impacts on the interlaminar fracture toughness of hybrid and stitched composites laminates. The findings from this study will help designers and manufacturers towards using natural fibre composites in structural and semi-structural components in terms of understanding their mechanical properties, as new composite based products emerge. Double cantilever beam (DCB) tests were carried out under Mode I loading to determine the crack growth resistance curves (R-curves) and the critical energy release rate values for both initiation $\left(\mathrm{G}_{\mathrm{IC} \text { init. }}\right)$ and propagation toughness $\left(\mathrm{G}_{\mathrm{IC} \text { prop. }}\right)$. The fracture mechanisms of the surface 
and the delamination of composites were characterised by using scanning electron microscopy (SEM) and X-ray computed micro-tomography $(\mu \mathrm{CT})$.

\section{Experimental procedure}

\subsection{Materials}

The matrix material used in this study was based on commercially available vinyl ester, trade name: Scott-Bader Crystic VE676-03, obtained from Scott-Bader. Accelerator was added at $2 \%$ by weight along with Triganox 239 at $2 \%$ by weight as the catalyst. Woven flax and woven basalt fibres were used as the reinforcements $\left(+/-45^{\circ}\right)$ biaxial stitched non-crimp fabrics of $600 \mathrm{~g} / \mathrm{m}^{2}$ in weight, supplied by Net Composites Ltd. A PTFE layer of $20 \mu \mathrm{m}$ thick was used to simulate a crack in the middle of reinforced panels. Table 1 presents the chemical and structural composition of different natural fibres commonly used as reinforcements in composites.

\subsection{Fabrication of composite laminates}

The flax and flax/basalt hybrid laminates were fabricated by the vacuum infusion technique. This technique is beneficial to produce composites with high volume fraction of fibres and it enables a better strength-to-weight ratio with less void content (4). The resininfused laminates were prepared using a balanced layup with the reinforcement of flax and basalt fibres, as illustrated in Fig. 1. The process started with the dry pack of layers which were placed on top of a glass plate which had previously been treated with a release agent (Multishield). This pack was then covered with a layer of nylon peel ply release and a diffusion mesh was added to the top of the peel ply to help shorten the infusion time. The tape rectangle was then covered with a vacuum bag, the inlet pipe capped off and a vacuum of -29 " $\mathrm{Hg}$ applied. Once the resin had been mixed with accelerator and catalyst, the inlet pipe was submerged in a container of resin and the pipe was uncapped, allowing the resin to be infused into the layup. Once set, the composite laminates were left to cure for 24 hours at ambient temperature followed by demoulding and post curing in an oven at $80{ }^{\circ} \mathrm{C}$ for 3 hours.

Three types of composite laminates were prepared namely, flax fibre reinforced vinyl ester (FVE), flax fibre hybridised basalt reinforced vinyl ester unstitched (FBVEu) and flax fibre hybridised basalt reinforced vinyl ester stitched (FBVEs). FBVEs panels were to have three straight lines at $2 \mathrm{~mm}$ intervals using machine stitching by cotton thread across their 
widths, starting at a distance of approximately $5 \mathrm{~mm}$ from the crack tip of the Teflon layer (see Fig. 2). The latter was inserted along the central axis of each panel in order to simulate a starter crack of the delamination and reduce friction between the top and bottom of cantilever beam. The average of fibre volume fraction of FVE, FBVEu and FBVEs was around 31\%, 33\% and $34 \%$ respectively. The void content was approximately 3\%. The physical and mechanical properties of reinforcing materials are summarised in Table 2. All specimens of composite materials were cut according to the requirements of each test, based on the geometry and dimension. The water jet method was used for cutting the specimens from the panels and then dried instantly at $50{ }^{\circ} \mathrm{C}$ for 24 hours to remove any surface moisture absorbed.

\subsection{Water absorption tests}

The effect of water absorption on Mode I interlaminar fracture toughness of FVE, FBVEu and FBVEs were investigated in accordance with BS EN ISO: 1999 to calculate the moisture uptake percentage and the diffusion coefficient of different composites. Five specimens of each sample type were placed in a desiccator for 48 hours and then weighed to the nearest $0.1 \mathrm{mg}$. This process was repeated until a constant mass was reached. The specimens were immersed in a container of de-ionised water at room temperature of $23 \pm 1^{\circ} \mathrm{C}$ for different time durations. After 24 hours from immersion, the specimens were taken out from the container of de-ionised water. Then the surface was dried with absorbent paper, re-measured and then put it back into the container immediately. The immersion time was continued for 42 days to ensure that it was enough to reach the equilibrium moisture content. The specimens were weighed at intervals of 24 hours up to 1008 hours exposure.

Water absorption percentage was calculated according to the following formula:

$$
M_{(\%)}=\frac{M_{t}-M_{0}}{M_{0}} \times 100
$$

Where $M_{(\%)}$, is the moisture uptake in percentage; $M_{t}$ is the weight of the water immersed specimens at a given time; $M_{0}$ is the initial weight of the sample at dry condition.

The diffusion coefficient (D) was calculated using the following equation:

$$
D=\frac{d^{2}}{\pi^{2} \times t_{70}}
$$

where $d$ is sample thickness (mm) and $t_{70}$ is time taken to reach $70 \%$ of saturation (s). 
The diffusion coefficient (D) is defined as the slope of the normalised mass uptake against square root of time $\sqrt{ } t$ and has the form:

$D=\pi\left(\frac{k h}{4 M_{m}}\right)^{2}$

where, $k$ is the initial slope of a plot of $\mathrm{M}(\mathrm{t})$ versus $\mathrm{t}^{1 / 2}, M_{m}$ is the maximum weight gain and $h$ is the thickness of the composite $(39,40)$.

\subsection{Mode I interlaminar fracture toughness testing}

The fracture toughness tests were conducted on a Zwick/Roell Z250 universal testing machine fitted with $5 \mathrm{kN}$ capacity load cell as per ASTM D5528 (41), as a specific standard for calculating $\mathrm{G}_{\mathrm{IC}}$ in woven fabric composites which does not yet exist (42). Mode I interlaminar fracture toughness $\left(\mathrm{G}_{\mathrm{IC}}\right)$ was measured using the double cantilever beam (DCB) method. The specimen geometry and dimensions are shown in Fig. 3. In Mode I, each specimen has two piano hinges with $25 \mathrm{~mm}$ of steel bonded on both sides (top and bottom) of the specimen end with mixed epoxy and hardener resin glue of 50\%. Before bonding the hinges, surfaces of both sides were cleaned with acetone and sanded with sandpaper. When the surfaces were dry the hinges were bonded by using a C-clamp to attach them in place for 48 hours. One side edge of each specimen was painted with white lacquer to assist optical crack length measurement. The crack initiation and growth was monitored using a digital camera with $3 \mathrm{x}$ magnifying lens. The load and displacement were recorded from the machine by testXpert software. The tests were carried out at a constant crosshead speed of $5 \mathrm{~mm} / \mathrm{min}$ in order to produce a stable crack growth. The test set up and the tool used to monitor the images during the test is shown in Fig.4. For each composite type, five specimens were tested to determine the average values of the initiation ( $\mathrm{G}_{\mathrm{IC}}$ init. $)$ and propagation toughness $\left(\mathrm{G}_{\mathrm{IC}}\right.$ prop.).

In Mode I, the DCB test was used to obtain the critical energy release rate, GIC, based on the theory of linear elastic fracture mechanics (LEFM) by using three data reduction methods (43). In the modified beam theory (MBT), rotation may occur at the crack tip because the beam is not perfectly fixed. Thus, the strain energy release rate $\mathrm{G}_{\mathrm{IC}}$ is calculated as follows:

$G_{\mathrm{I} c}=\frac{3 P \delta}{2 b(a+|\Delta|)}$

where $P$ is the applied load $(\mathrm{N}), \delta$ the load point displacement $(\mathrm{mm})$ and $a$ the delamination length $(\mathrm{mm})$, and $b$ is the specimen width $(\mathrm{mm})$. The crack length correction factor, $\Delta$ is obtained by plotting the cube root of compliance, $C^{1 / 3}$ as a function of delamination length $a$. The compliance, $C$ is the ratio of the load point displacement to the applied load $(\delta / P)$. In 
addition, the compliance calibration (CC) was the second method for DCB to measure the corrected energy release rate $\mathrm{G}_{\mathrm{IC}}$ as shown:

$G_{\mathrm{I} c}=\frac{n P \delta}{2 b a}$

where $a$ is the delamination length and $n$ is the linear slope of least-square fit of $\log (C)$ versus $\log (a)$. With the modified compliance calibration (MCC) method, the normalised value of the delamination length is used which is equal to $a / h$, where $h$ is the thickness of the beam. The graph of the delamination length normalised as a function of the cube root of compliance, $C^{1 / 3}$, is plotted using visually observed delamination of the initiation values and all the propagation values. The slope of this line is denoted as $n$. The interlaminar fracture toughness for the MCC is calculated using the equation below:

$G_{\mathrm{I} c}=\frac{3 P^{2} C^{2} / 3}{2 n b h}$

\subsection{Scanning electron microscopy (SEM)}

The fractured surfaces of the dry and wet samples after the DCB tests were examined in order to study the effect of moisture absorption in delamination behaviour of the composite specimens using a SEM JSM 6100 at room temperature. After adhering to SEM stubs, a thin layer of gold/palladium is applied to the specimens prior to SEM examination. The micrographs of the delamination provide important information on how the specimens fail in relation to fibre-matrix adhesion and resulting failure mechanisms.

\subsection{X-ray computed micro-tomography $(\mu \mathrm{CT})$}

The nature of the damage evolution in a composite structure is a complex phenomenon that includes delamination, matrix cracking, fibre pull-out and breakage. To effectively analyse these defects, high quality instruments are required $(44,45)$. X-ray computed microtomography $(\mu \mathrm{CT})$ measurements were performed using a Nikon (Xtec) XTH225 to obtain fracture damage characterisation through the thickness of the laminates. $\mu \mathrm{CT}$ methods were used to reconstruct the three-dimensional structure of the samples from a large number of $\mathrm{X}$ ray projection images. VGStudio MAX was used to extract images and the X-ray source powered at $110 \mathrm{kV}-110 \mathrm{uA}$. 


\section{Results and discussion}

The experimental results obtained from this study are divided into three parts. The first part evaluates the sorption behaviour and the diffusion coefficient of flax and basalt fibres hybrid composites along with stitched composite specimens. The second part investigates the effect of water absorption on the interlaminar fracture toughness of FVE, FBVEu and FBVEs composite laminates by using Mode I (DCB) tests. In the last part, the fracture damage mechanisms at the surface and delamination of these composite specimens are examined using SEM and micro CT scan.

\subsection{Sorption behaviour}

Fig. 5 shows the moisture absorption curves of three different composites (FVE, FBVEu and FBVEs), where each data point represents the mean value of each specimen type. The percentage of weight gain as a function of square root of time immersed in de-ionised water at room temperature of $23 \pm 1{ }^{\circ} \mathrm{C}$ for $1008 \mathrm{hrs}$ (42 days) as shown in Fig. 5 exhibits that for all the composite specimens, the moisture uptake at the beginning is linear and rapidly increases then slows down for a prolonged time until saturation reaches a plateau around $900 \mathrm{hrs}$ (5 weeks). The moisture uptake results show Fickian behaviour at room temperature. The maximum weight gain percentages of FVE, FBVEs and FBVEu composite specimens were 5.38\%, 3.70\% and $3.57 \%$, respectively. Both types of FBVEu and FBVEs samples showed similar water absorption behaviours due to same balanced layup technique used, except for the small amount of stitched fibre. It is noted that stitching of natural fibres through-thickness reinforcement would cause an increase of a small percentage of water absorption which might affect the stitching performance and mechanical properties. The saturation moisture uptake of FVE composites without hybridisation were much more than FBVEu composites by approximately $50 \%$. This indicates that flax fibre absorbed moisture quickly which caused swelling of the fibre due to high cellulose of a hydrophilic nature (46). As a result, fibre swelling can cause micro-cracking in the brittle thermosetting polymer matrix composites. It is well established that the mechanical properties of water immersed natural fibre reinforced composites are reduced with increasing ageing time due to weak fibre-matrix interface created by the water ingress process. This can further promote the swelling of fibres as well as plasticisation of matrices which in turn results in the reduction of strength and stiffness for water immersed specimens compared to dry specimens. 
Moreover, moisture penetration occurred into the composite interface because of the diffusion of water molecules inside the micro gaps between polymer chains (7). For basalt hybridisation of FBVEu composites, the basalt fibre has helped to prevent water penetrating into the fibre-matrix interface as it has better water repellence behaviour compare to FVE specimens (17).

The diffusion coefficient is a kinetic parameter which describes the capability of solvent molecules to move through the polymer segments. Table 3 illustrates the diffusion coefficients of FVE, FBVEs and FBVEu composites immersed in de-ionised water. It is observed that the maximum moisture content and the diffusion coefficient values decrease with hybridised FBVE composites compared to non-hybridisation composites of FVE by $50 \%$ and $44 \%$, respectively. This is attributed to the external basalt layers in FBVE composite specimens which protect the internal layers from degradation during ageing environmental exposure. On the other hand, FVE composites shrink, expand and debond between the fibre and matrix which creates voids acting as water reservoirs and thus raising the saturation level. Similar observations have been recently reported for flax (10 layers) and flax/basalt (6 flax layers in the middle, 4 basalt layers as external skins, 2 each side) laminates (18). Their results highlighted that the percentage of water uptake for flax fibre composite is higher than flax/basalt composite, and both reached saturation level after 4 weeks of ageing as similarly reported (17).

\subsection{Effect of moisture absorption on Mode I interlaminar fracture toughness}

Crosshead-load and displacement curves $(P-\delta)$ for both dry and water-aged samples of FVE, FBVEu and FBVEs composite specimens were obtained from the DCB test. The plotted curves for different specimens can be classified into three stages as shown in Fig. 6. Firstly, the linearity of the load to the displacement of all samples occurred when the load was $128 \mathrm{~N}$. For FVE and FBVEu specimens linearity stopped at load $175 \mathrm{~N}$ and $141 \mathrm{~N}$ respectively, after recorded displacement of $2 \mathrm{~mm}$ showing much resistance to deformation before the initiation of crack. In this elastic deformation stage (I), there is no visual damage or any crack initiation as depicted in Fig. 7 (I). Secondly, the curves showed an increased nonlinear behaviour in load with increased displacement. The crack initiation for FVE, FBVEu and FBVEs dry composites were visually observed at load $211.97 \mathrm{~N}, 187.24 \mathrm{~N}$ and $171.37 \mathrm{~N}$ respectively. When the crack first visibly initiated from the white lacquer of the crack tip zone, the load and displacement were recorded after crack initiation, as shown in Fig. 7 (II). The load required to initiate crack 
is lower for the water immersed specimens compared to their dry counterparts. For example, the load required to initiate crack of FVE wet specimens was $30 \%$ lower than that of dry FVE specimens. For flax basalt hybrid specimens, the load required for water immersed specimens was $15 \%$ lower than that of dry specimens. The lower load for crack initiation for wet specimens is attributed to weak fibre- matrix interface due to moisture ingress (7). It is worth noting that the load required to initiate crack for flax basalt hybrid specimens was much higher than that of flax alone without basalt hybrid specimens. This improvement is attributed to higher stiffness and better dimensional stability at wet conditions of basalt fibre as well as their water repellence behaviour. It can be seen that aged samples show less resistance to crack initiation that unaged samples. Thirdly, a maximum load plateau occurs before complete failure and the crack propagates as shown ductile behaviour materials. All sample types exhibited that a stable crack propagation occurred with constant crosshead rate except stitched composites. It was observed that extensive fibre bridging occurred during the crack propagation with a slight deviation in the path of the crack, as clearly illustrated in Fig. 7 (III). This implies that imitations of these cracks created load reduction and then lead to delamination failure and fibre breakage. In the case of stitched, both dry and wet composites have the lowest displacement. The crack propagation is unstable beyond the peak load. This is because the existence of stitch threads create voids when needle inserts the through-thickness reinforcement, and then decreases the stiffness of the composite due to damage caused to woven fibres (26).

\subsubsection{Delamination crack growth resistance curve}

The experimental resistance curves (R-curve) which presents the relationship between the Mode I strain energy release rate $\left(\mathrm{G}_{\mathrm{IC}}\right)$ and the delamination length (a), were obtained to determine the initiation and propagation of a crack length in both dry and wet specimens. Referring to the results of other research works carried out on Mode I (DCB) tests $(47,48)$, three different data reduction methods of MBT, CC and MCC were employed based on the standard to determine the interlaminar fracture toughness. Each of the samples exhibited similar properties using different methods where this validates the reliability of the data obtained from the experimental results in this study. Fig. 8 shows the crack growth resistance curves for three groups of samples: a) FVE, b) FBVEu and c) FBVEs.

Considering the FVE samples as shown in Fig. 8 (a), an increase of GIC can be seen in the crack zone between $52 \mathrm{~mm}$ to $62 \mathrm{~mm}$ and then it changes to less steep with steady-state between $62 \mathrm{~mm}$ to $74 \mathrm{~mm}$. All three methods are very close to each other and some points for 
$\mathrm{CC}$ and MCC coincide. The crack length grew up to $24 \mathrm{~mm}$ and $20 \mathrm{~mm}$ of FVE dry and wet respectively, with reasonable constant speed in stable state. In wet conditions, the fracture toughness decreased with crack propagation up to $70 \mathrm{~mm}$. It can be noted that less resistance to crack propagation was shown by FVE wet composites compared with the dry ones. This is because of the high percentage of cellulose and hemicellulose consisting of flax fibres that are susceptible to absorbing more water into their hydrophilic properties, which causes weak fibre matrix interface bonding (49). For these FBVEu specimens in Fig. 8 (b), the GIC values for the dry composites increased almost in a linear form of crack length from $50 \mathrm{~mm}$ to $62 \mathrm{~mm}$. However, there are different behaviours for those water-aged samples, especially in the region between $52 \mathrm{~mm}$ and $54 \mathrm{~mm}$ : curves are steeper and then decrease after $54 \mathrm{~mm}$. The data reduction methods CC and MCC are equal together in dry composites between $53 \mathrm{~mm}$ and 62 $\mathrm{mm}$, while those of the MBT run parallel to them. The crack lengths of FBVEu dry composites were higher than wet laminates with approximately $12 \mathrm{~mm}$ and $9 \mathrm{~mm}$ respectively. However, the characteristic behaviour for the interlaminar fracture toughness GIC values are different due to more water ingress into the flax fibres in the middle of the starter crack before the crack tip zone that could affect the fracture toughness initiation for their properties rather than the propagation. The results presented demonstrate that hygrothermal conditioning has a significant effect on the delamination and crack growth.

In the case of stitched composites of FBVEs as shown in Fig. 8 (c), these results imply that the stitched composites have the lowest crack length with only $5 \mathrm{~mm}$ because of the barrier against further crack propagation of stitched yarn, unlike the unstitched sample FBVEu. The curves of $\mathrm{CC}$ and MCC are almost linear and parallel to the slopes but MBT curves are quite apart from them for both dry and wet samples. Once the crack growth has been initiated on FBVEs laminates, the fracture toughness then increases until the stitched zone as shown between $52 \mathrm{~mm}$ to $55 \mathrm{~mm}$. It was found that stitching has significantly decreased the fracture toughness propagation due to the arrest of crack propagation in the stitched zone, in comparison to the unstitched. This observation can be explained by placing stitch thread that decreases the stiffness of the composite due to damage caused to fibres and resins when a needle punches in the laminates, as shown in Fig. 9. Hence, the presence of stitching through-thickness reinforcement caused high stress concentrations and created resin-rich pockets (50). 


\subsubsection{Fracture energy}

The average values from Mode I strain energy release rates for $\mathrm{G}_{\mathrm{IC}}$ init. and $\mathrm{G}_{\mathrm{IC}}$ prop. are shown in Fig. 10 using different reduction MBT, CC and MCC methods of FVE, FBVEu and FBVEs dry and wet composite laminates. In all cases, the modified beam theory (MBT) has the lowest value for both initiation and propagation toughness. In Fig. 10 (a), the results showed that the interlaminar fracture toughness of $\mathrm{G}_{\mathrm{IC}}$ init. for FVE wet laminates were significantly decreased by approximately $26.77 \%$; it can be noticed that there is less resistance to crack propagation at the onset of crack tip with water-aged samples. Similarly, the fracture energy of $\mathrm{G}_{\mathrm{IC}}$ init. for FBVEu wet composites was significantly decreased with an average of $23 \%$ compared to dry samples, as shown in Fig. 10 (b). The reason for that could be due to high moisture absorption by flax fibres in the delamination of Teflon inserted through the plies of the composites during water immersion, which leads to the weak fibre-matrix interface. The other factor that might affect the delamination resistance of $\mathrm{G}_{\mathrm{IC}}$ init. for FVE and FBVEu wet composites are poor interfacial bonding between matrix and fibre (20). With crack growth, the

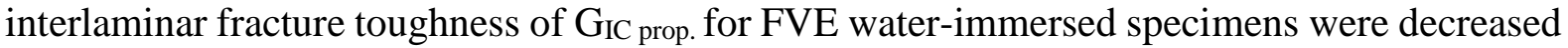
by an average of $10.30 \%$, compared to FVE dry samples. However, the GIC prop. of FBVEu wet laminates had increased on average by $15.35 \%$, compared to dry composite laminates, as shown in Fig.10 (b). An initial explanation could be attributed to the hybridisation of basalt layers that showed better resistance to crack propagation. The type of resin shows some positive effect on the water absorption. For example, vinyl ester composites have much resistance to water penetration (51). For stitched samples of FBVEs laminates, the fracture energy of GIC init. and $\mathrm{G}_{\mathrm{IC}}$ prop. for wet samples were increased by an average of $4.28 \%$ and $19.63 \%$ respectively. It was observed that even though basalt hybridisation improved the delamination strength but, because of the high crack closure load exerted by stitches, the interlaminar fracture properties are reduced (26). This study showed that the presence of stitches led to a notable reduction in the interlaminar fracture toughness of $\mathrm{G}_{\mathrm{IC}}$ init. and $\mathrm{G}_{\mathrm{IC}}$ prop. resulting in the points of initiation and propagation being close to each other, as represented in R-curves shown in Fig. 8 (c).

The results of the interlaminar fracture toughness of initiation and propagation for dry and wet composite specimens using MBT, $\mathrm{CC}$ and $\mathrm{MCC}$ are summarised in data table in Fig.10. Fracture toughness of FVE dry composites is the highest at propagation with an average of $12093.12 \mathrm{~J} / \mathrm{m}^{2}$, indicating that woven flax fibres play an important role as toughening material. For FBVEu wet laminates, the fracture toughness of GIC prop. was slightly higher than FVE wet composites with an average of $11232.68 \mathrm{~J} / \mathrm{m}^{2}$ and $10846.98 \mathrm{~J} / \mathrm{m}^{2}$ respectively. This 
could be attributed to the basalt hybridisation that provides a better shield to the swelled flax fibres. In the case of FBVEu wet samples, it is observed that interlaminar fracture toughness initiation has more energy absorbed than FVE and FBVEs composites. This can be explained in terms of high amounts of water absorption in the delamination of the starter crack zone before the crack tip causes swelling fibres that fill the gaps between the fibre and polymer matrix and then could lead to increase the interlaminar fracture properties of GIC init. This study showed that flax fibre without hybridised and stitched has higher interlaminar fracture toughness. Reported works on the effect of stitching on carbon and glass fibre composites suggest that stitching has contributed towards the improvement on crack arrest and load bearing capability $(25,26)$. With this concept, it was expected that FBVEs laminates should have greater load-bearing capability and higher fracture energy than that of FVE composites. However, this improvement was not observed on the stitched samples. The reasons could have been due to that fact that the stitch thread was strong to the extent of causing a permanent location of high stress concentration and resin-rich pockets (50). Hence, the initial and primary crack of the stitched specimen changed to secondary and longitudinal crack these primaryoriented secondary cracks would have caused the final failure. As a result, the interlaminar fracture toughness of initiation and propagation for FBVEs dry and wet laminates had significantly decreased compared to FVE and FBVEu composites. The $\mu \mathrm{CT}$ evidence shown in Fig. 11 supports this observation. Clearly, the results of this study are in reasonable agreement with the weft-knitted glass fabrics shown in (52), indicating that interlaminar fracture toughness of woven flax composites (6 layers) was double than that of glass woven fabric composites (10 layers).

\subsection{Morphology study on the fractured surfaces}

In order to differentiate fractured surfaces between dry and water-immersed specimens, the delaminated surfaces were observed by using a scanning electron microscope (SEM). Fig. 12 shows SEM micrographs of the fractured surfaces for dry composites laminates after Mode I (DCB) failure. It is evident that there is more fibre breakage and fracture surfaces in FVE composites resulting from the poor fibre-matrix interfacial bonding; the flax fibres tend to agglomerate into bundles and are then unequally dispersed through the matrix (see Figs. 12 a and b). Fibre pull-out and splitting deformed fibres from the matrix in FBVEu composites could be seen, and there are some broken fibres on the delaminated surfaces shown in Fig. 12 (c). Extensive in-plane fibre-bridging exists in the stitched zone after crack growth, high stress concentrations at the interface of FBVEs laminates which caused fibre-matrix debonding and 
led to unstable crack propagation, are shown in Fig. 12 (f). This is evidence confirmed by xray imaging of stitching through-thickness reinforcement causing localised in-plane fibre damage due to needle penetration of woven fabric (50). Therefore, the interlaminar fracture toughness of stitched laminates significantly drop compared to unstitched samples. Moreover, further fracture occurred for FBVEs composites and voids induced by fibre pull-out are clearly seen in Fig. 12 (e). At higher magnification (Fig. 12d) large in-plane fracture for fibre bundles of stitched composites can be seen, and a substantial amount of energy was absorbed by fibre breakage and fibre bridging mechanisms during delamination. These micro-scale results commonly occurred on Mode I (DCB) tests $(33,53)$.

SEM micrographs of delaminated surfaces for water-aged samples are shown in Fig. 13. It can be clearly observed that exposure to moisture without hybridisation results in a decrease in the fracture toughness properties due to degradation and cavities of the fibre-matrix interface. The presence of water in the environment can create moisture-induced cavities and surface degradation as indicated on the fractured surfaces. This scenario can cause microcracking and debonding in the composites and reduce the fracture toughness of the composites as a result of a weak fibre-matrix interface. Micro-cracking and debonding caused by large amounts of water ingress for FVE composites as illustrated in Figs. 13 (a) and (b). As expected, the addition of basalt fibre on flax as hybrid material, the water repellence property has been enhanced. As a result, a large toughness enhancement has arisen from FBVEu specimens. In flax/basalt hybrid specimens (FBVEu), a resistance to delamination has occurred on the surface without much matrix cracking at the fibre-matrix interface, especially in the crack propagation zone (see Fig. 13 c). Fracture and fibre breakage happened mostly at the fibre-matrix interface as revealed by the bare fibres and fibre imprints in the matrix. The delaminated surfaces indicate poor interfacial bonding (Fig. $13 \mathrm{~d}$ ) and fibre matrix adhesion as a result of water molecules ingress is the primary mode of failure for water-immersed specimens. In the case of stitched samples, resin-rich pockets and matrix deformation are observed in Fig. 13 (e) as a result of needle-punching during the stitching procedure (54). Thus, high stress concentration around stitch fibres caused fibre damage and then reduced the fracture toughness initiation and propagation of FBVEs laminates. A large number of fragmented matrix are observed in this stitched sample which allowed fracture and pull-out of non-aligned fibres (Fig. $13 \mathrm{f}$ ). Furthermore, higher amounts of stitched fibres might cause in-plane fibre misalignment and resin-rich regions (26). 


\section{Conclusions}

Mode I interlaminar fracture toughness of FVE, FBVEu and FBVEs composites were examined using MBT, CC and MCC methods to quantify the effects of water absorption on fracture toughness behaviour. The experimental findings showed that the fracture toughness values for initiation and propagation of FVE wet composites without hybridisation were decreased compared to dry samples. However, the fracture toughness for propagation of FBVEu water-aged composites was increased, with decreased crack initiation because of the basalt hybridisation that provided a better shield to the swelled flax fibres. The reason for a decrease in the crack initiation is due to high moisture absorption by flax fibres leading to a weak fibre-matrix interface. The resistance curve (R-curve) of FVE and FBVEu wet composites showed that the crack growth length is shorter than the dry samples. The modified beam theory (MBT) has the lowest and most conservative value for both initiation and propagation toughness for all specimens.

Dry and wet composites of FBVEs have the lowest crack length and crack growth behaviour from stable propagation to stick-slip unstability. It was found that even though basalt hybridisation improved the delamination strength, because of high crack closure loads exerted by the stitches, the interlaminar fracture properties are reduced. Both FVE and FBVE composites showed saturation after 960 hours of ageing. Moisture absorption and the diffusion coefficient of hybrid composites show less absorption compared to over non-hybrid composites by approximately $50 \%$ and $44 \%$, respectively. The fracture mechanisms showed energy dissipation through matrix deformation, fibre pull-out, fibre debonding, and fibre breakage. The analysed results of this study revealed that using basalt fibre as external layers onto flax reinforced composites can improve the interlaminar fracture toughness. This shows that basalt fibre hybridisation can be used as an effective method to enhance the mechanical properties, durability and the moisture resistance of natural fibre composites.

\section{References}

1. Hughes M, Hill CAS, Hague JRB. The fracture toughness of bast fibre reinforced polyester composites. Part 1 Evaluation and analysis. J Mater Sci. 2002;7:4669-76.

2. Dhakal HN, Skrifvars M, Adekunle K, Zhang ZY. Falling weight impact response of jute/methacrylated soybean oil bio-composites under low velocity impact loading. Compos Sci Technol. Elsevier Ltd; 2014;92:134-41.

3. Shah DU. Developing plant fibre composites for structural applications by optimising 
composite parameters: a critical review. J Mater Sci. 2013;48(18):6083-107.

4. Yan L, Chouw N, Jayaraman K. Flax fibre and its composites - A review. Compos Part B Eng. Elsevier Ltd; 2014 Jan;56:296-317.

5. Dittenber DB, Gangarao HVS. Critical review of recent publications on use of natural composites in infrastructure. Compos Part A Appl Sci Manuf. Elsevier Ltd; 2012;43(8):1419-29.

6. Faruk O, Bledzki AK, Fink H-P, Sain M. Biocomposites reinforced with natural fibers: 2000-2010. Prog Polym Sci. Elsevier Ltd; 2012 Nov;37(11):1552-96.

7. Dhakal HN, Zhang ZY, Richardson MOW. Effect of water absorption on the mechanical properties of hemp fibre reinforced unsaturated polyester composites. Compos Sci Technol. 2007;67:1674-83.

8. Zamri MH, Akil HM, Bakar a. a., Ishak Z a. M, Cheng LW. Effect of water absorption on pultruded jute/glass fiber-reinforced unsaturated polyester hybrid composites. J Compos Mater. 2011 Sep 21;46(1):51-61.

9. Anandjiwala RD, Vries A De, Sadiku ER, Wyk L Van, Africa S. Effect of water absorption on mechanical properties of flax fibre reinforced composites. In: 6th International conference on composite science and technology. Durban, South Africa; 2007. p. 1-10.

10. Zulki R, Fatt LK, Azhari CH, Sahari J. Interlaminar fracture properties of fibre reinforced natural rubber / polypropylene composites. J Mater Process Technol. 2002;128:33-7.

11. Hughes M, Carpenter J, Hill C. Deformation and fracture behaviour of flax fibre reinforced thermosetting polymer matrix composites. J Mater Sci. 2007;42:2499-511.

12. Goutianos S, Peijs T, Nystrom B, Skrifvars M. Development of Flax Fibre based Textile Reinforcements for Composite Applications. Appl Compos Mater. 2006 Jun 16;13(4):199-215.

13. Davoodi MM, Sapuan SM, Ahmad D, Ali A, Khalina A, Jonoobi M. Mechanical properties of hybrid kenaf/glass reinforced epoxy composite for passenger car bumper beam. Mater Des. Elsevier Ltd; 2010 Dec;31(10):4927-32.

14. Fiore V, Di Bella G, Valenza A. Glass-basalt/epoxy hybrid composites for marine applications. Mater Des. Elsevier Ltd; 2011;32(4):2091-9.

15. Dhakal HN, Zhang ZY, Guthrie R, Macmullen J, Bennett N. Development of flax/carbon fibre hybrid composites for enhanced properties. Carbohydr Polym. Elsevier Ltd.; 2013 Jul 1;96(1):1-8.

16. Nunna S, Chandra PR, Shrivastava S, Jalan A. A review on mechanical behavior of natural fiber based hybrid composites. J Reinf Plast Compos. 2012 Jun 14;31(11):759_ 69.

17. Fiore V, Scalici T, Calabrese L, Valenza A, Proverbio E. Effect of external basalt layers on durability behaviour of flax reinforced composites. Compos Part B Eng. Elsevier Ltd; 2016;84:258-65. 
18. Fiore V, Scalici T, Badagliacco D, Enea D, Alaimo G, Valenza A. Aging resistance of bio-epoxy jute-basalt hybrid composites as novel multilayer structures for cladding. Compos Struct. Elsevier Ltd; 2016;160:1319-28.

19. Wei B, Cao H, Song S. Tensile behavior contrast of basalt and glass fibers after chemical treatment. Mater Des. Elsevier Ltd; 2010;31(9):4244-50.

20. Li Y, Mai Y-W, Ye L. Effects of fibre surface treatment on fracture-mechanical properties of sisal-fibre composites. Compos Interfaces. 2005;12:141-63.

21. Silva RV, Spinelli D, Bose Filho WW, Claro Neto S, Chierice GO, Tarpani JR. Fracture toughness of natural fibers/castor oil polyurethane composites. Compos Sci Technol. 2006 Aug;66(10):1328-35.

22. Santhanam V, Chandrasekaran M. Studies on fracture toughness of Banana-Glass fibre hybrid composite. Indian J Eng. 2014;11(26):21-9.

23. Wong S, Shanks R a., Hodzic A. Mechanical behavior and fracture toughness of poly(L-lactic acid)-natural fiber composites modified with hyperbranched polymers. Macromol Mater Eng. 2004;289:447-56.

24. Almansour FA, Dhakal HN, Zhang ZY, Ghasemnejad H. Effect of hybridization on the mode II fracture toughness properties of flax/vinyl ester composites. Polym Compos. 2015 Aug;

25. Tan K, Watanabe N, Iwahori Y. Stitch fiber comparison for improvement of interlaminar fracture toughness in stitched composites. J Reinf Plast Compos. 2010 Sep 7;30(2):99-109.

26. Velmurugan R, Solaimurugan S. Improvements in Mode I interlaminar fracture toughness and in-plane mechanical properties of stitched glass/polyester composites. Compos Sci Technol. 2007 Jan;67(1):61-9.

27. Beier U, Fischer F, Sandler JKW, Altstädt V, Weimer C, Buchs W. Mechanical performance of carbon fibre-reinforced composites based on stitched preforms. Compos Part A Appl Sci Manuf. 2007 Jul;38(7):1655-63.

28. Jain LK. On the effect of stitching on Mode I delamination toughness of laminated composites. Compos Sci Technol. 1994;51:331-45.

29. Sankar B V, Sharmab SK. Mode II delamination toughness of stitched graphite/epoxy textile composites. Compos Sci Technol. 1997;57:729-37.

30. Khan MZS, Mouritz AP. Fatigue behaviour of stitched GRP laminates. Compos Sci Technol. 1996 Jan;56(6):695-701.

31. Velmurugan R, Gupta NK, Solaimurugan S, Elayaperumal A. The effect of stitching on FRP cylindrical shells under axial compression. Int J Impact Eng. 2004 Sep;30(89):923-38.

32. Mouritzas AP, Leongb KH, Herszbergc I. A review of the effect of stitching on the inplane mechanical properties of fibre-reinforced polymer composites. Compos Part A Appl Sci Manuf. 1997;(28):979-91. 
33. Ravandi M, Teo WS, Tran LQN, Yong MS, Tay TE. The effects of through-thethickness stitching on the Mode I interlaminar fracture toughness of flax/epoxy composite laminates. Mater Des. Elsevier Ltd; 2016 Nov;109:659-69.

34. Placet V, Trivaudey F, Cisse O, Gucheret-Retel V, Boubakar ML. Diameter dependence of the apparent tensile modulus of hemp fibres: A morphological, structural or ultrastructural effect? Compos Part A Appl Sci Manuf. Elsevier Ltd; 2012;43(2):275-87.

35. Thygesen A, Oddershede J, Lilholt H, Thomsen AB, Stahl K. On the determination of crystallinity and cellulose content in plant fibres. Cellulose. 2005 Dec 20;12(6):56376.

36. Saheb DN, Jog JP. Natural fiber polymer composites: a review. Adv Polym Technol. 1999;18:351-63.

37. $\mathrm{Li} \mathrm{W}, \mathrm{Xu}$ J. Mechanical properties of basalt fiber reinforced geopolymeric concrete under impact loading. Mater Sci Eng A. 2009 Apr;505(1-2):178-86.

38. Zhang Y, Li Y, Ma H, Yu T. Tensile and interfacial properties of unidirectional flax/glass fiber reinforced hybrid composites. Compos Sci Technol. Elsevier Ltd; 2013 Nov;88:172-7.

39. Crank J. the Mathematics of Diffusion. 2nd edition, Oxford University Press, UK. 1975.

40. Espert A, Vilaplana F, Karlsson S. Comparison of water absorption in natural cellulosic fibres from wood and one-year crops in polypropylene composites and its influence on their mechanical properties. Compos Part A Appl Sci Manuf. 2004;35(11):1267-76.

41. ASTM D5528. Mode I interlaminar fracture toughness of unidirectional fiber reinforced polymer matrix composites. 2007. p. ASTM D5528.

42. Hamer S, Leibovich H, Green A, Avrahami R, Zussman E, Siegmann A, et al. Mode I and Mode II fracture energy of MWCNT reinforced nanofibrilmats interleaved carbon/epoxy laminates. Compos Sci Technol. Elsevier Ltd; 2014 Jan;90:48-56.

43. Prasad MSS, Venkatesha CS, Jayaraju T. Experimental Methods of Determining Fracture Toughness of Fiber Reinforced Polymer Composites under Various Loading Conditions. J Miner Mater Charact Eng. 2011;10:1263-75.

44. Růžek R, Lohonka R, Jironč J. Ultrasonic C-Scan and shearography NDI techniques evaluation of impact defects identification. NDT E Int. 2006 Mar;39(2):132-42.

45. Schilling PJ, Karedla BR, Tatiparthi AK, Verges M a., Herrington PD. X-ray computed microtomography of internal damage in fiber reinforced polymer matrix composites. Compos Sci Technol. 2005;65(14):2071-8.

46. Bismarck A, Aranbefwi-askargorta I, Berlin TU, Lampkfc T, Wielage B, Unwersit R. Surface Characterization of Flax, Hemp and Cellulose Fibers; Surface Properties and the Water Uptake Behavior. Polym Compos. 2002;23(5):872-94.

47. Hadavinia H, Ghasemnejad H. Effects of Mode-I and Mode-II interlaminar fracture 
toughness on the energy absorption of CFRP twill/weave composite box sections. Compos Struct. Elsevier Ltd; 2009 Jun;89(2):303-14.

48. Campilho R, Moura DC, Gonçalves DJS, da Silva J, Banea MD, da Silva LFM. Fracture toughness determination of adhesive and co-cured joints in natural fibre composites. Compos Part B Eng. 2013;50:120-6.

49. Biagiotti J, Puglia D, Kenny JM. A Review on Natural Fibre-Based Composites-Part I. J Nat Fibers. 2004 Oct 12;1(2):37-68.

50. Dransfield K, Baillie C, Mai Y. Improving the delamination resistance of CFRP by stitching. A Review. Compos Sci Technol. 1994;50:305-17.

51. Kim HJ, Seo DW. Effect of water absorption fatigue on mechanical properties of sisal textile-reinforced composites. Int J Fatigue. 2006;28(10 SPEC. ISS.):1307-14.

52. Falconnet D, Bourban PE, Pandita S, Månson JAE, Verpoest I. Fracture toughness of weft-knitted fabric composites. Compos Part B Eng. 2002;33(8):579-88.

53. Alif N, Carlsson LA, Boogh L. The effect of weave pattern and crack propagation direction on mode I delamination resistance of woven glass and carbon composites. Compos Part B Eng. 1998;29(5):603-11.

54. Aymerich F, Onnis R, Priolo P. Analysis of the fracture behaviour of a stitched singlelap joint. Compos Part A Appl Sci Manuf. 2005 May;36(5):603-14. 
Fig. 1. Schematic illustration of the stacking sequence of flax and flax/basalt hybrid laminates using a balanced layup.

Fig. 2. Schematic representation of the stitching pattern through-thickness reinforcement for DCB used in this study.

Fig. 3. The geometry of the double cantilever beam (DCB) specimen for mode $I\left(\mathrm{G}_{\mathrm{IC}}\right)$ testing (all dimensions in $\mathrm{mm}$ ).

Fig. 4. Mode I double cantilever beam (DCB) test set up.

Fig. 5. Water absorption as a function of time for DCB specimens of FVE, FBVEu and FBVEs composite laminates exposed to de-ionised water at room temperature.

Fig. 6. Load vs. displacement curves of Mode I dry and wet samples for FVE, FBVEu and FBVEs specimens.

Fig. 7. Series stages of FVE dry composites at mid-plane interface of DCB test a) Elastic deformation I, b) Crack initiation II, c) Crack propagation III.

Fig. 8. Resistance curves (R-curve) of Mode I (DCB) test for both dry and wet samples of a) FVE, b) FBVEu and c) FBVEs composite specimens using MBT, CC and MCC methods.

Fig. 9. Computed micro-tomography ( $\mu \mathrm{CT}$ ) images of FBVEs samples illustrating the reconstructed 2D slice in $x-z$ plane for a) Front and b) Back face.

Fig. 10. Mode I strain energy release rates for initiation $\mathrm{G}_{\mathrm{IC}}$ and propagation $\mathrm{G}_{\mathrm{IC}}$ toughness obtained from DCB tests for both dry and wet samples of a) FVE, b) FBVEu and c) FBVEs composite specimens using MBT, CC and MCC.

Fig. $11 \mathrm{X}$-ray $\mu \mathrm{CT}$ reconstructed cross section of FBVEs sample in y-z plane.

Fig. 12. SEM micrographs of the fracture surfaces for dry composites showing (a) longitudinal breakage for FVE, (b) bundle of flax fibres, (c) fibre pull out and fibre fractured of FBVEu, (d) fractured breakage and cotton stitch thread of FBVEs, (e) fractured flax stitch and voids, (f) fibre bridging of FBVEs.

Fig. 13. SEM micrographs of the fracture surfaces for wet composites showing (a) Moisture induced cavity for FVE composite, (b) surface degradation due to moisture presence of FVE, (c) delamination of FBVEu, (d) fibre breakage of FBVEu, (e) resin rich pocket with matrix cracking of FBVEs, (f) fractured fibre and matrix cracking of FBVEs. 


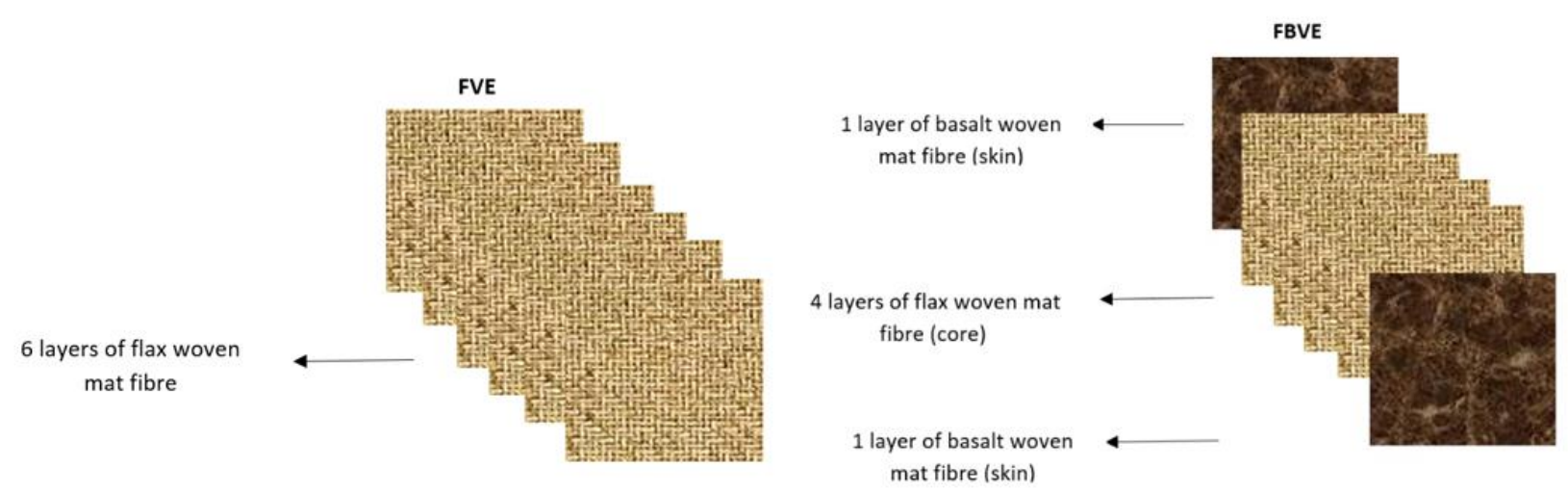

Fig. 1. Schematic illustration of the stacking sequence of flax and flax/basalt hybrid laminates using a balanced layup. 


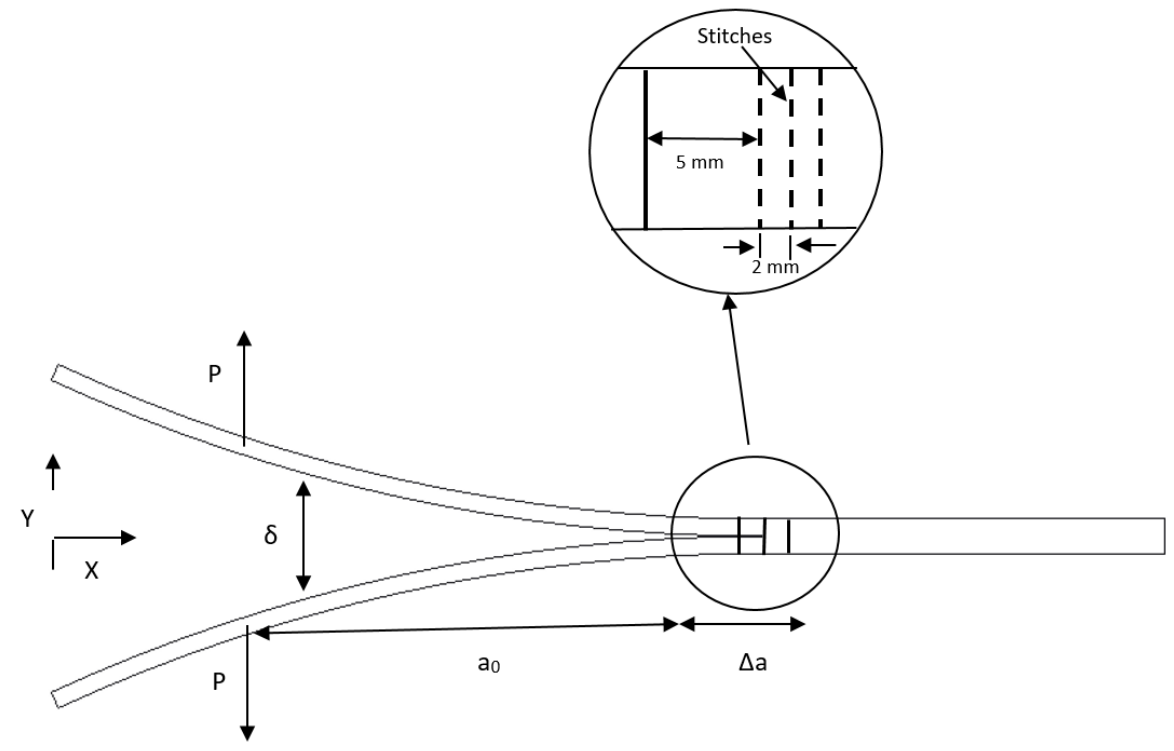

Fig. 2. Schematic representation of the stitching pattern through-thickness reinforcement for DCB used in this study. 


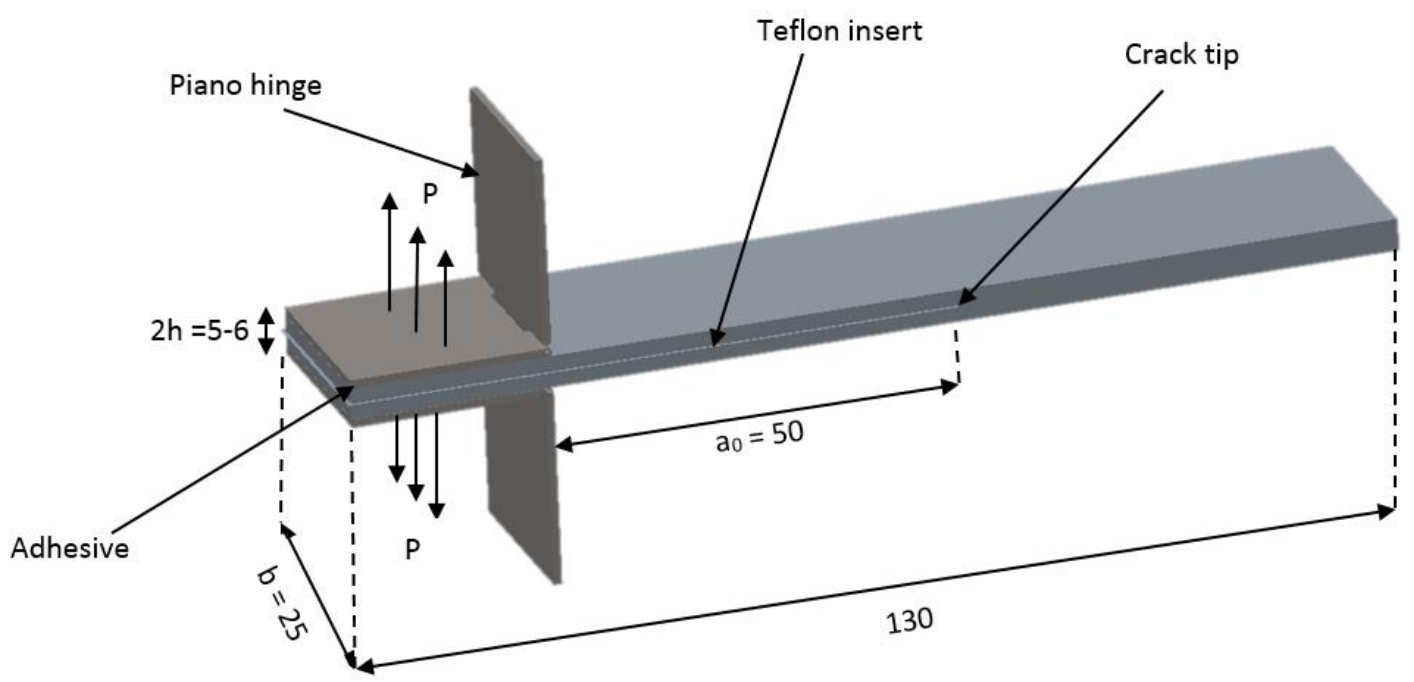

Fig. 3. The geometry of the double cantilever beam (DCB) specimen for mode $\mathrm{I}\left(\mathrm{G}_{\mathrm{IC}}\right)$ testing (all dimensions in $\mathrm{mm}$ ). 


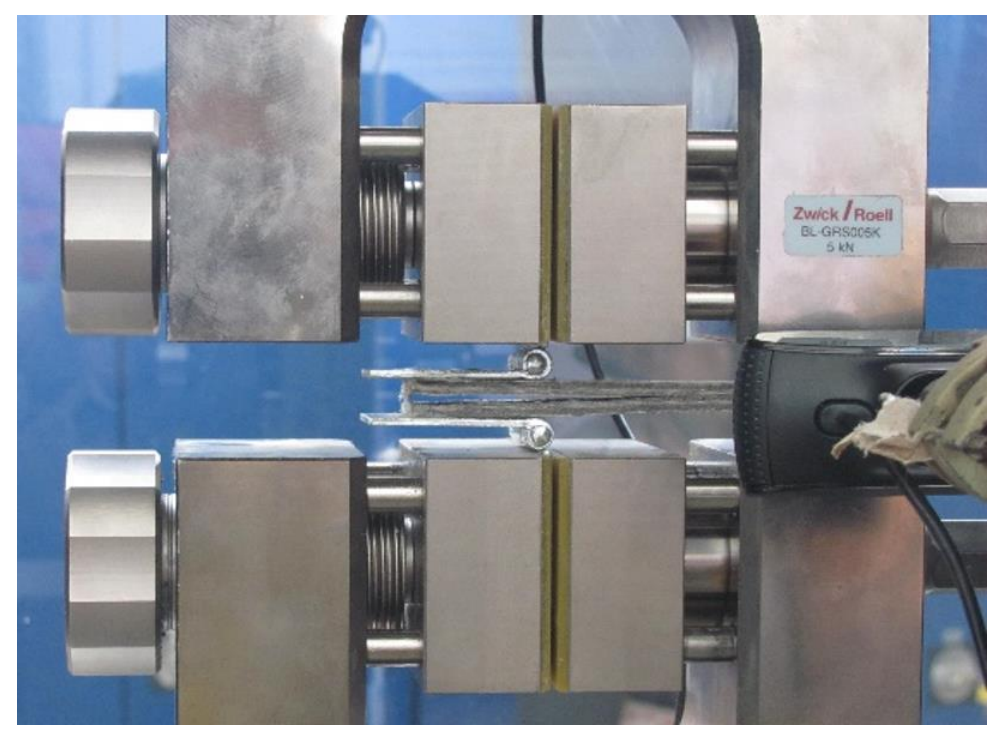

Fig. 4. Mode I double cantilever beam (DCB) test set up. 


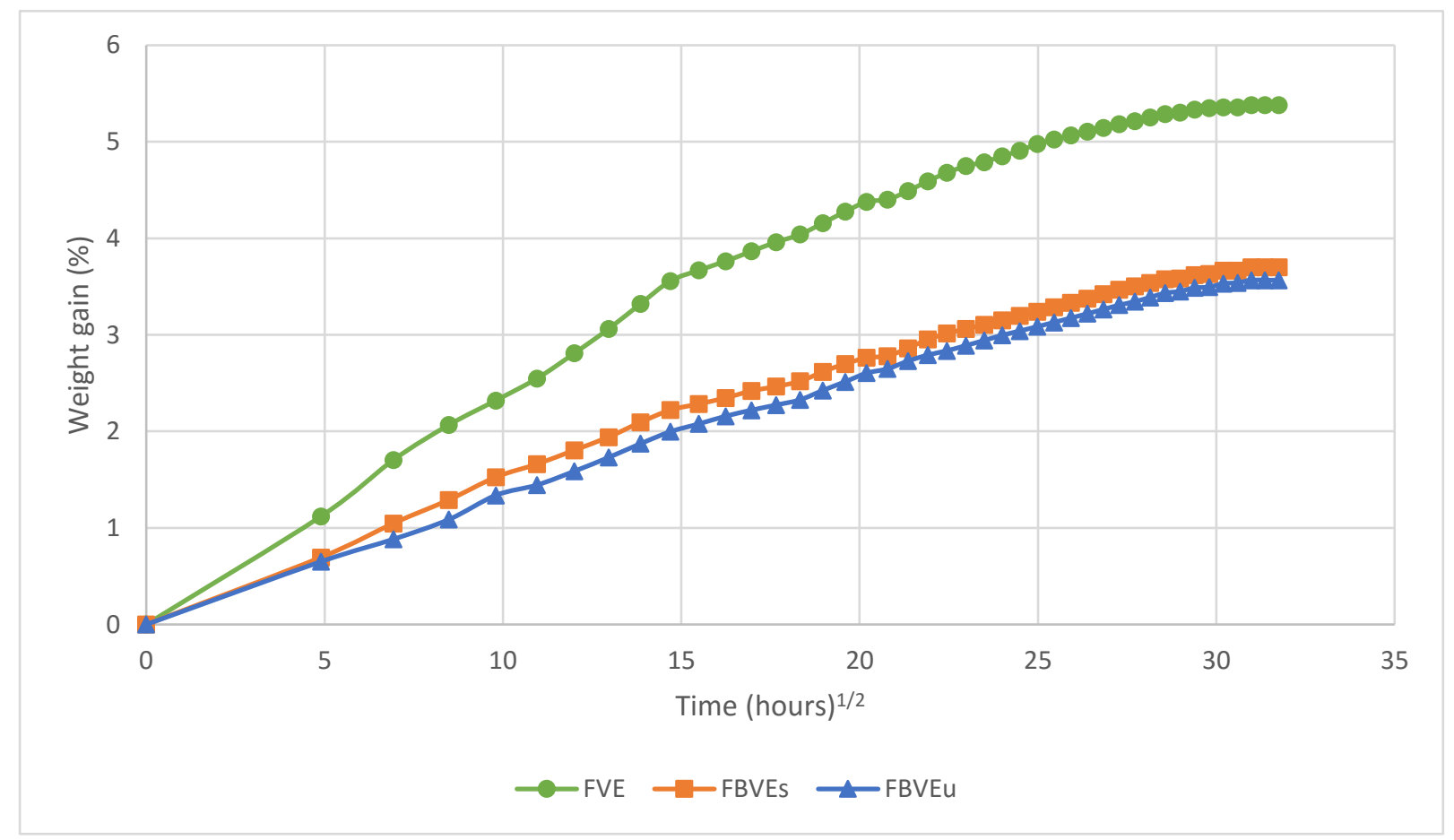

Fig. 5. Water absorption as a function of time for DCB specimens of FVE, FBVEu and FBVEs composite laminates exposed to de-ionised water at room temperature. 


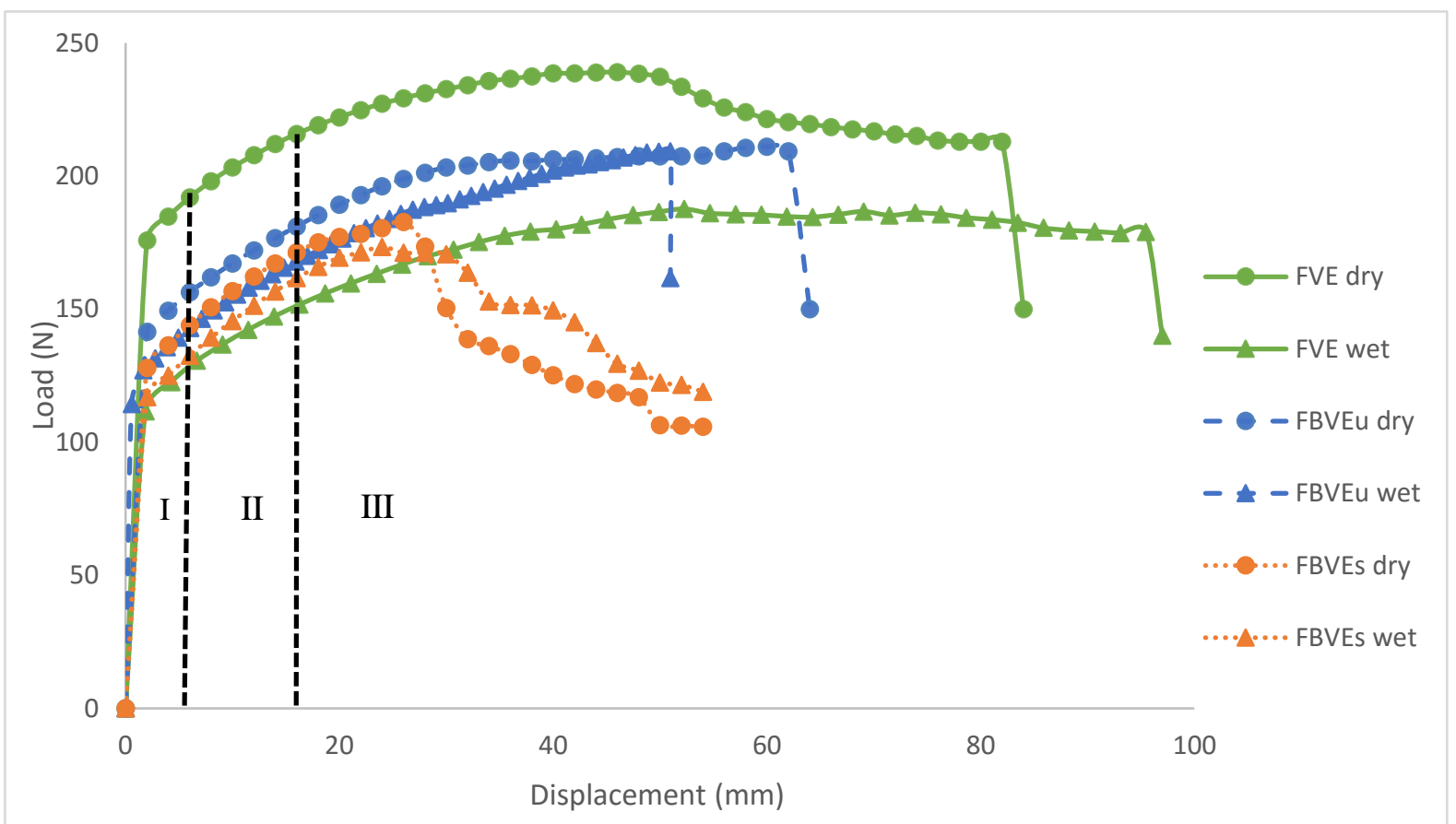

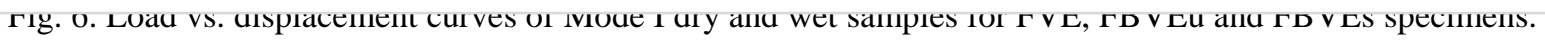



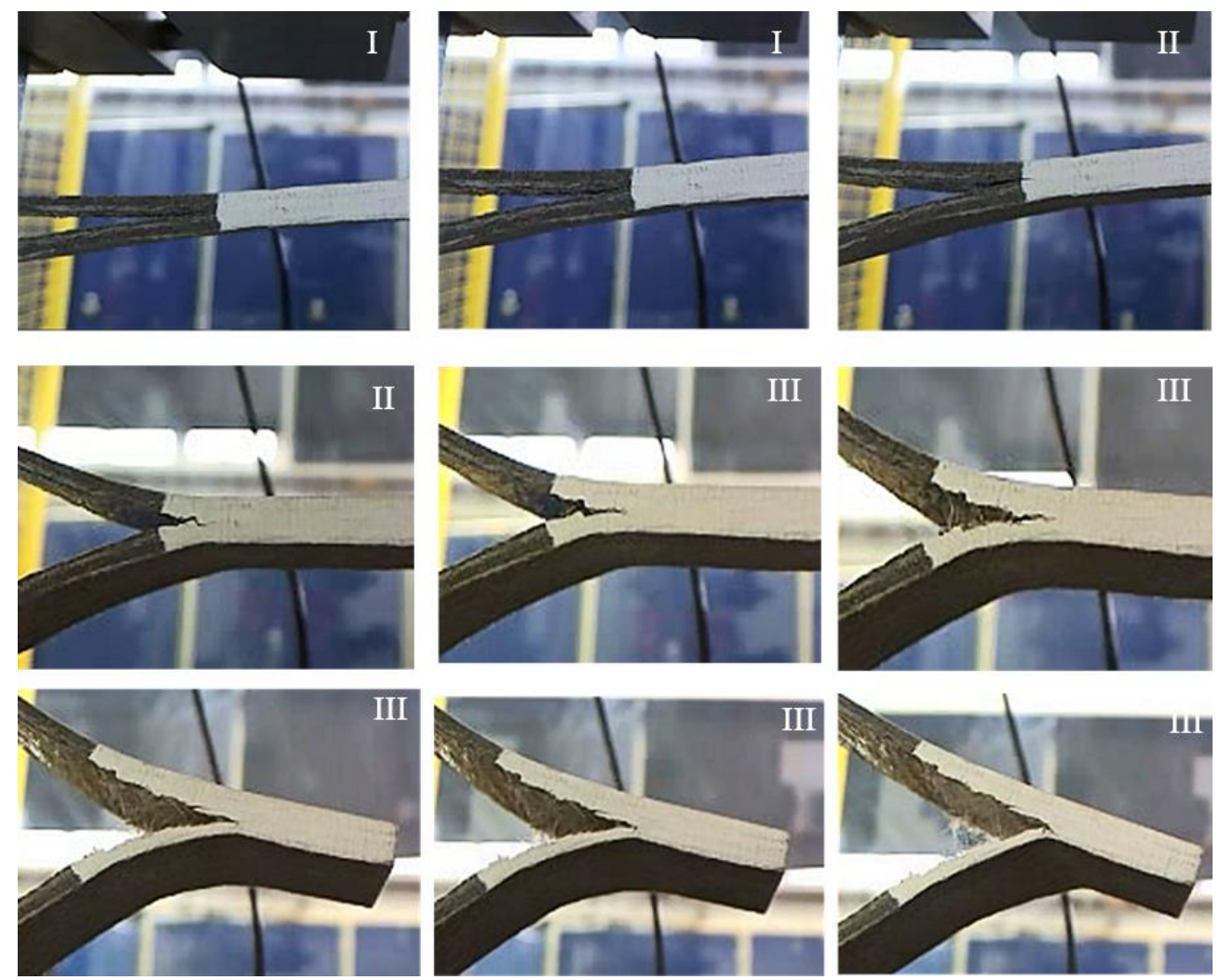

Fig. 7. Series stages of FVE dry composites at mid-plane interface of DCB test a) Elastic deformation I, b) Crack initiation II, c) Crack propagation III. 


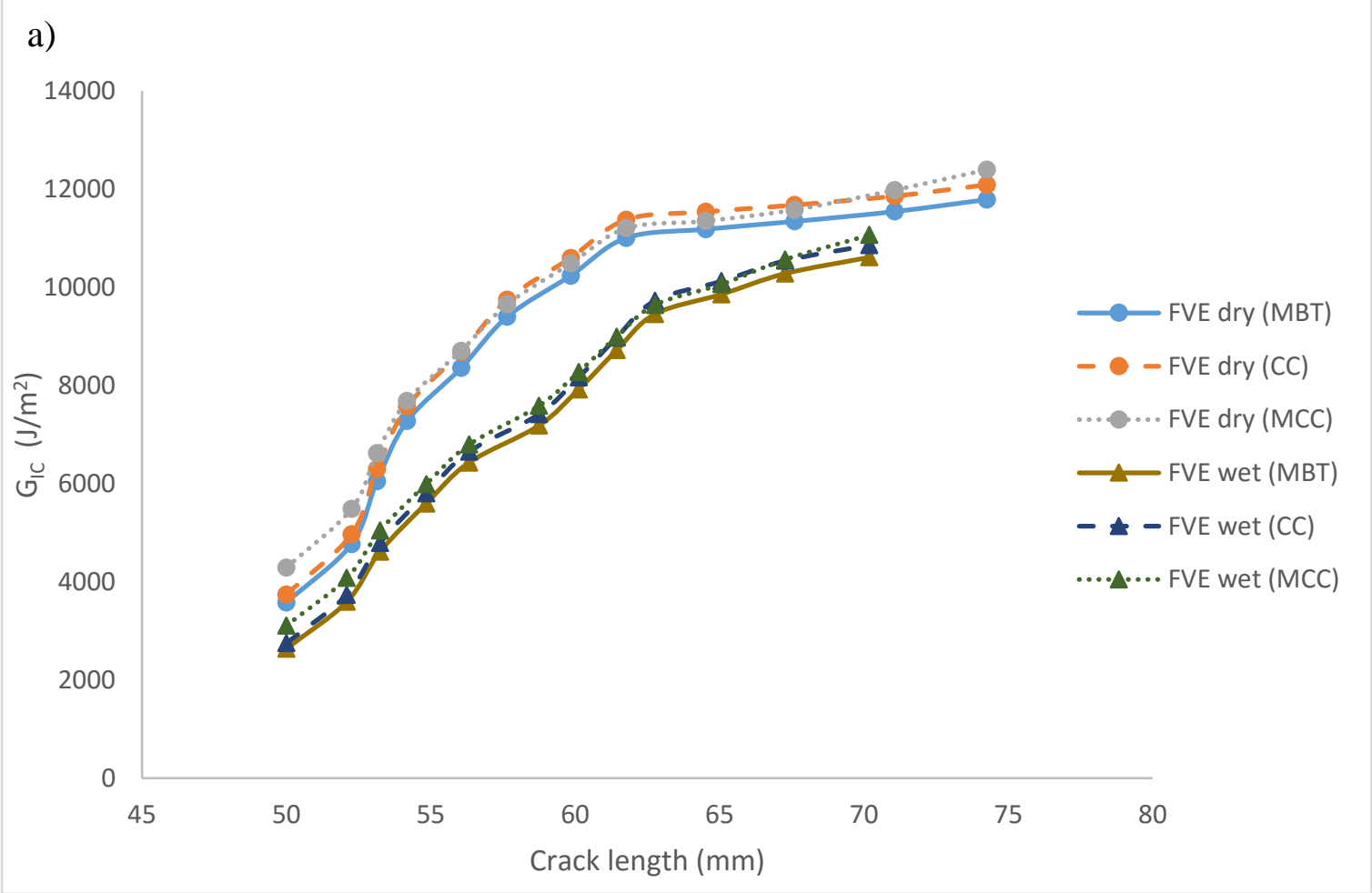

b)

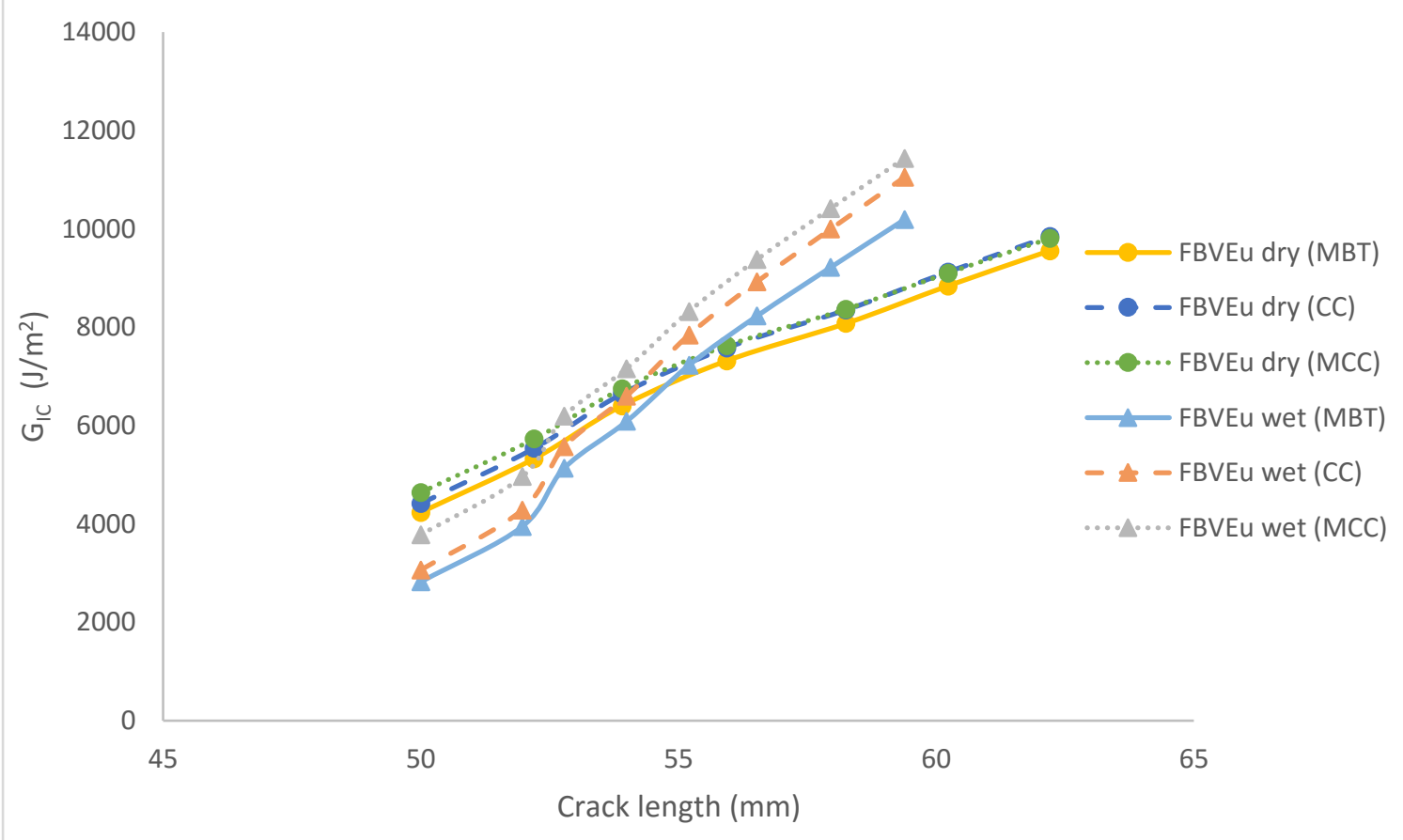




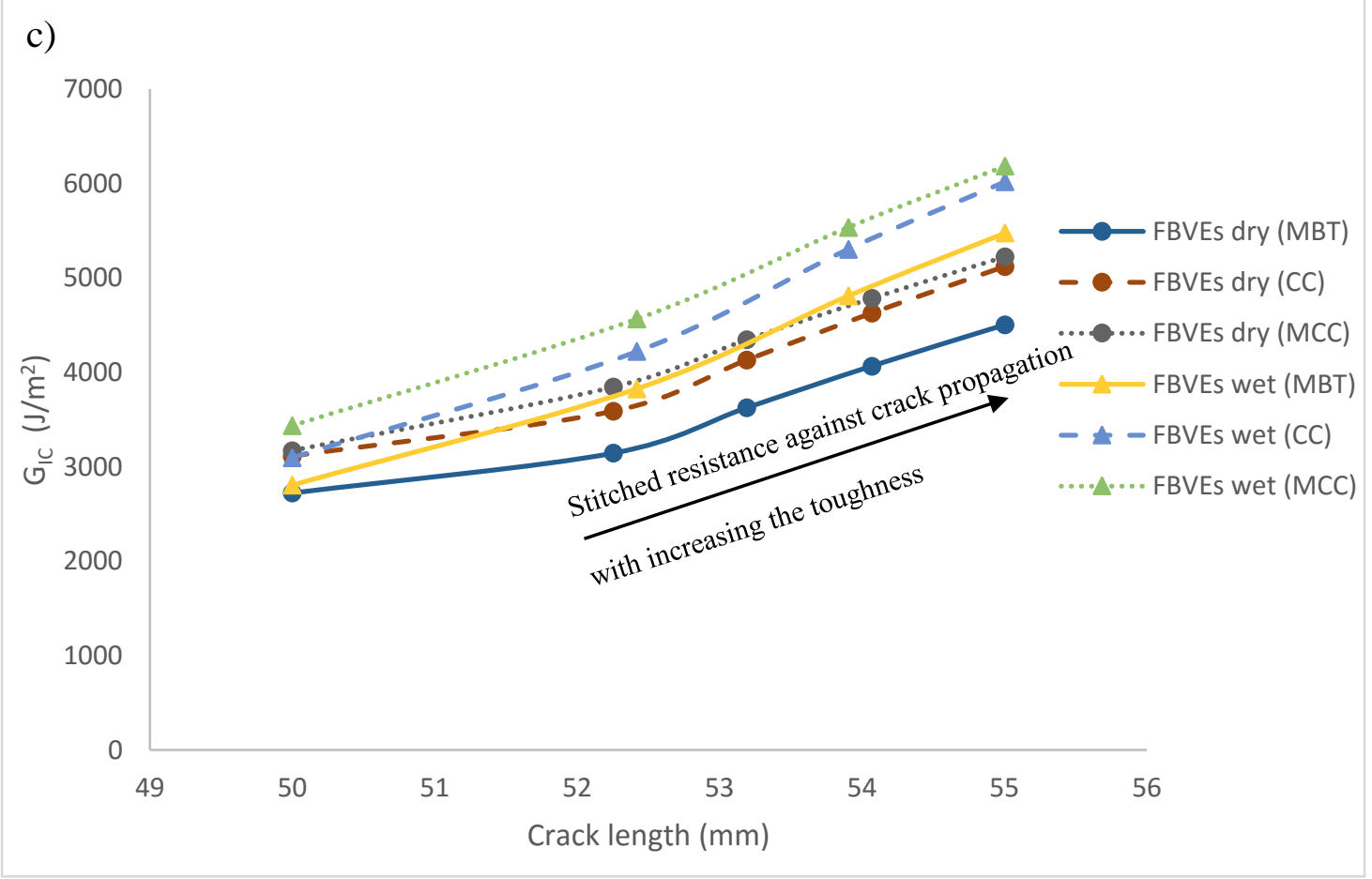

Fig. 8. Resistance curves (R-curve) of Mode I (DCB) test for both dry and wet samples of a) FVE, b) FBVEu and c) FBVEs composite specimens using MBT, CC and MCC methods. 

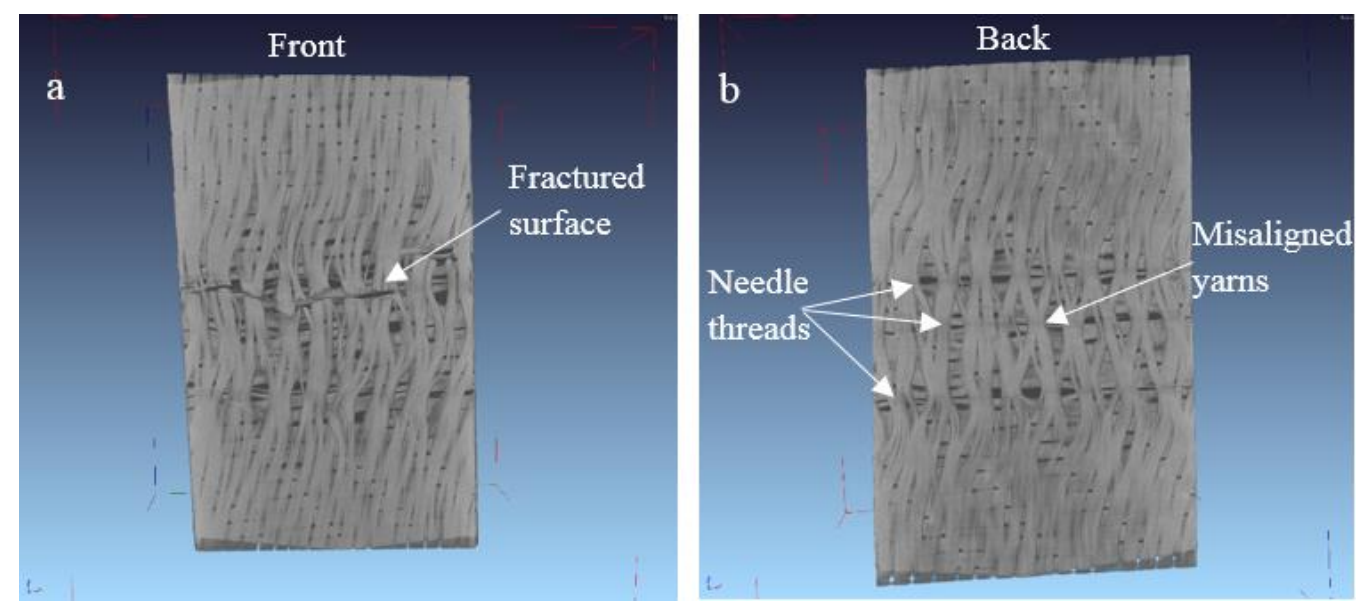

Fig. 9. Computed micro-tomography $(\mu \mathrm{CT})$ images of FBVEs samples illustrating the reconstructed 2D slice in X-z plane for a) Front and b) Back face. 


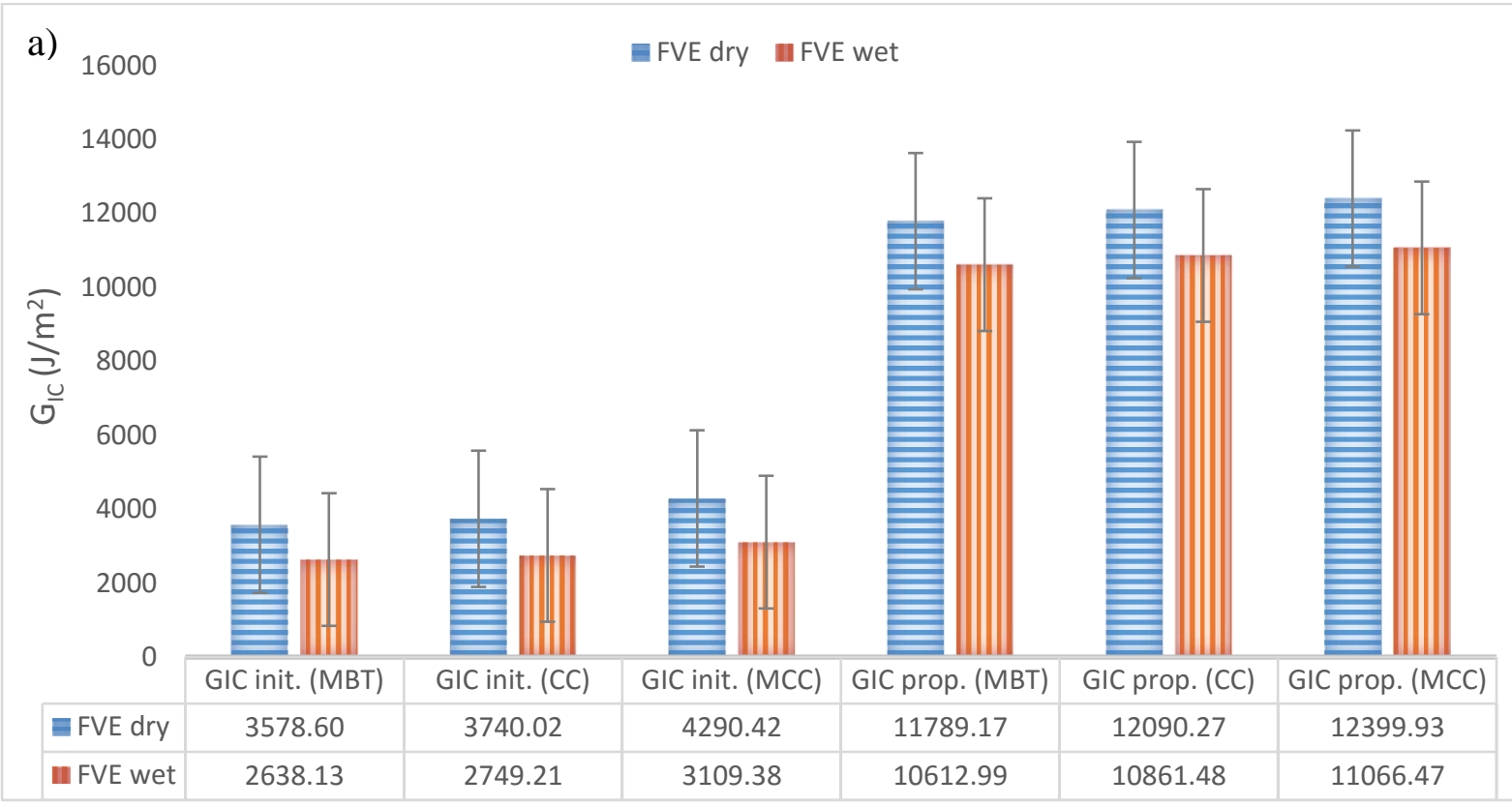




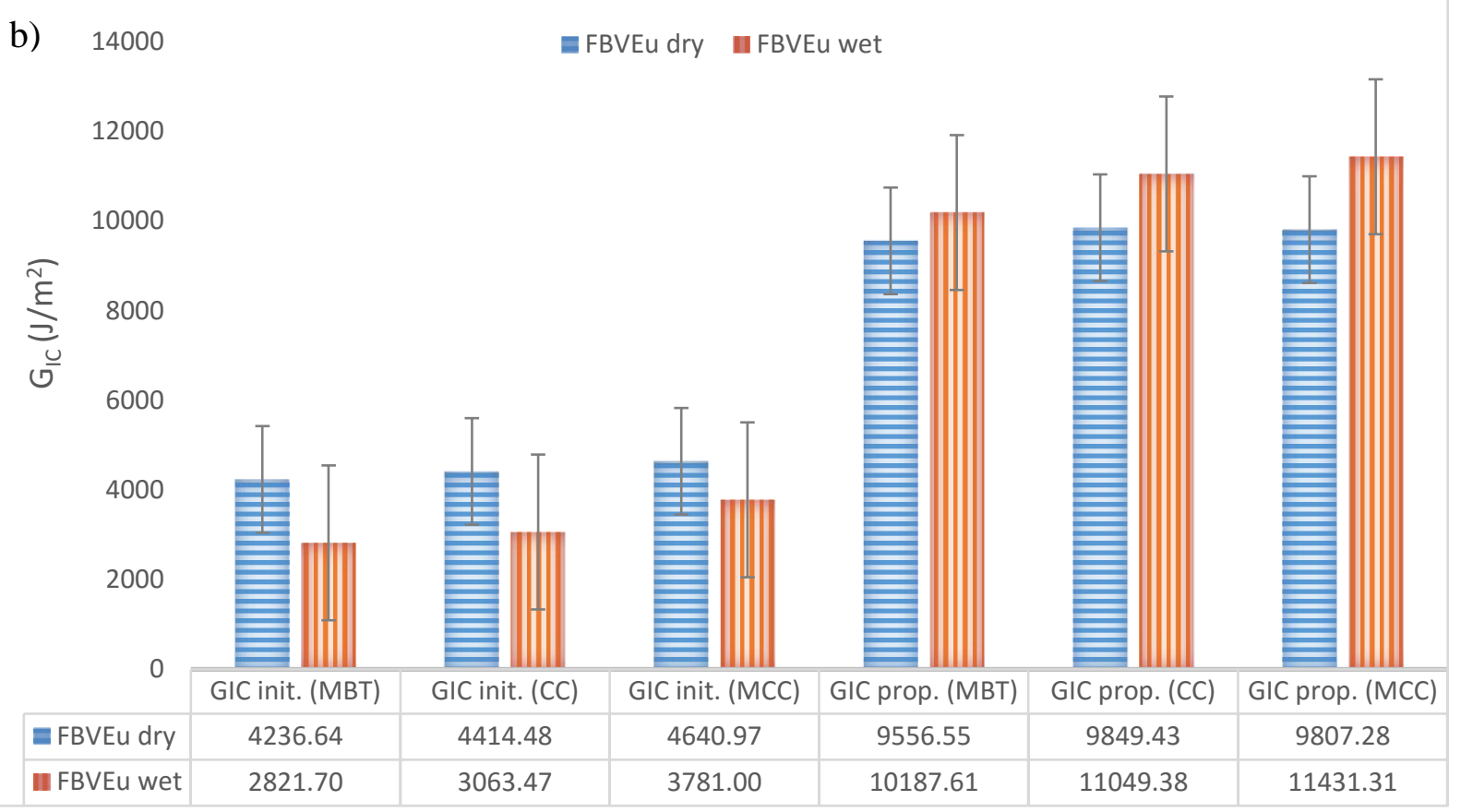




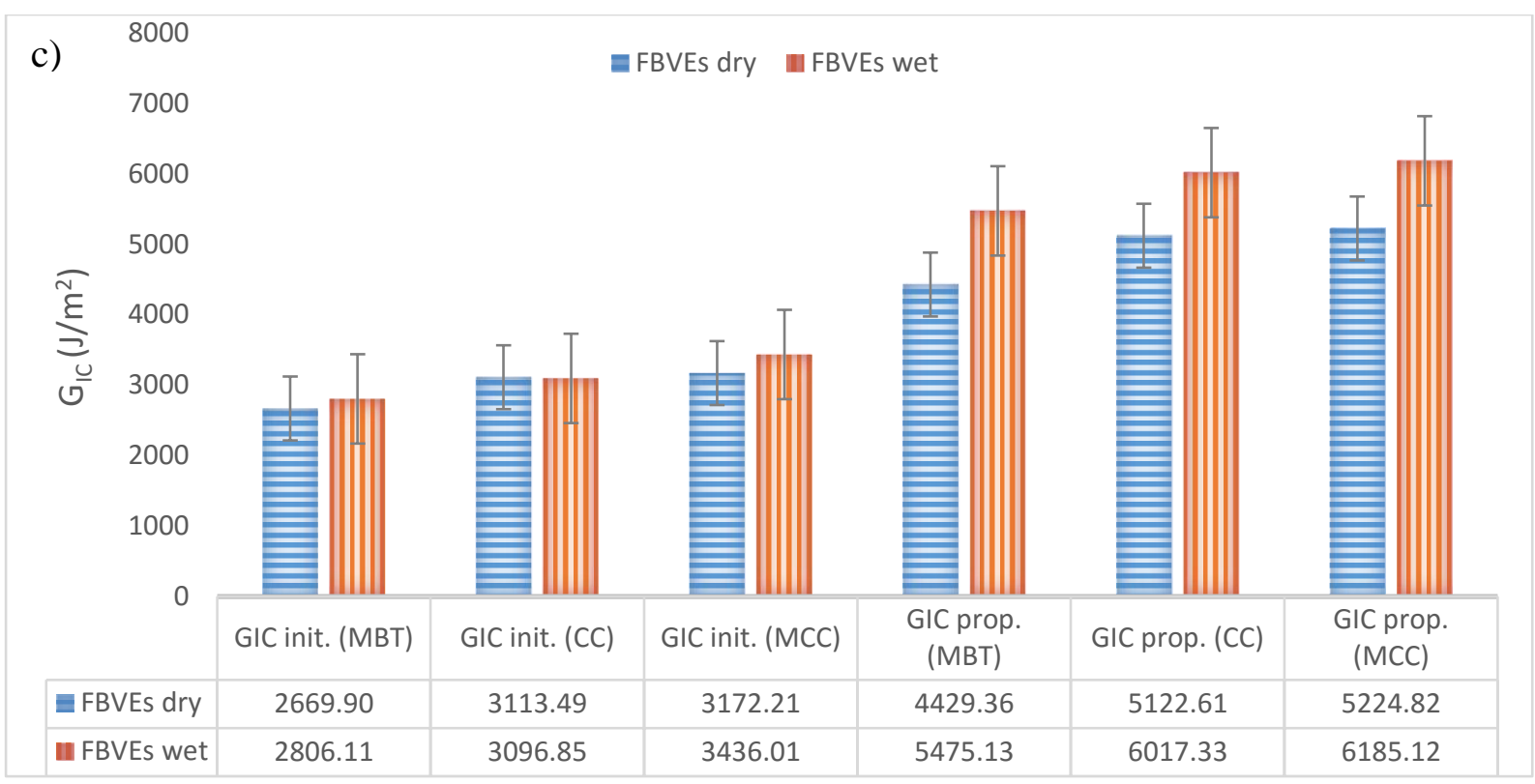

Fig. 10. Mode I strain energy release rates for initiation $\mathrm{G}_{\mathrm{IC}}$ and propagation $\mathrm{G}_{\mathrm{IC}}$ toughness obtained from DCB tests for both dry and wet samples of a) FVE, b) FBVEu and c) FBVEs composite specimens using MBT, CC and MCC. 


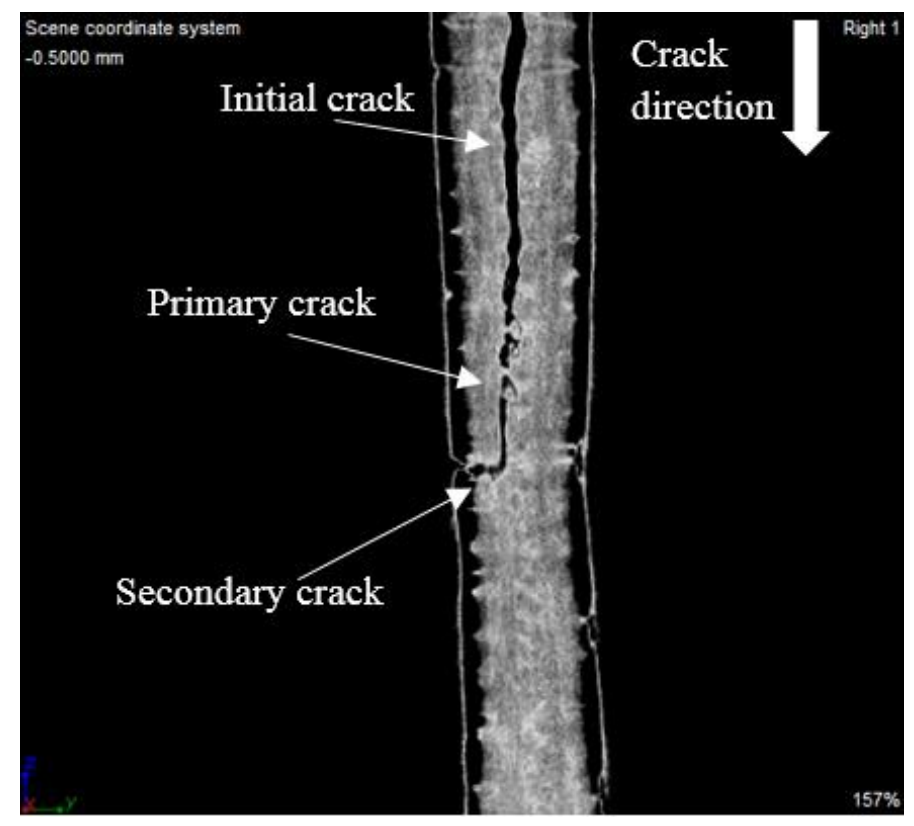

Fig. $11 \mathrm{X}$-ray $\mu \mathrm{CT}$ reconstructed cross section of FBVEs sample in $\mathrm{y}$-z plane. 


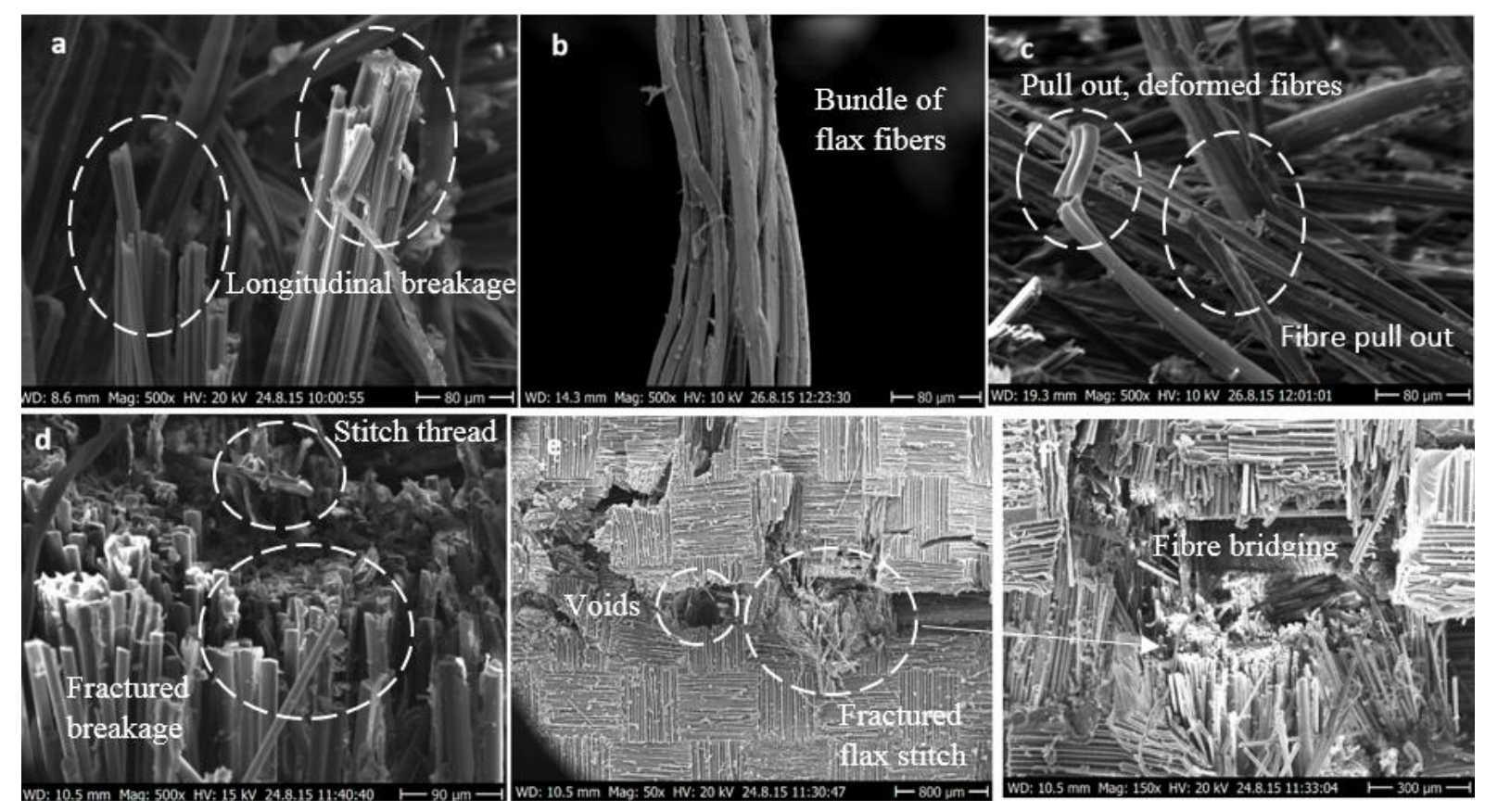

Fig. 12. SEM micrographs of the fracture surfaces for dry composites showing (a) longitudinal breakage for FVE, (b) bundle of flax fibres, (c) fibre pull out and fibre fractured of FBVEu, (d) fractured breakage and cotton stitch thread of FBVEs, (e) fractured flax stitch and voids, (f) fibre bridging of FBVEs. 

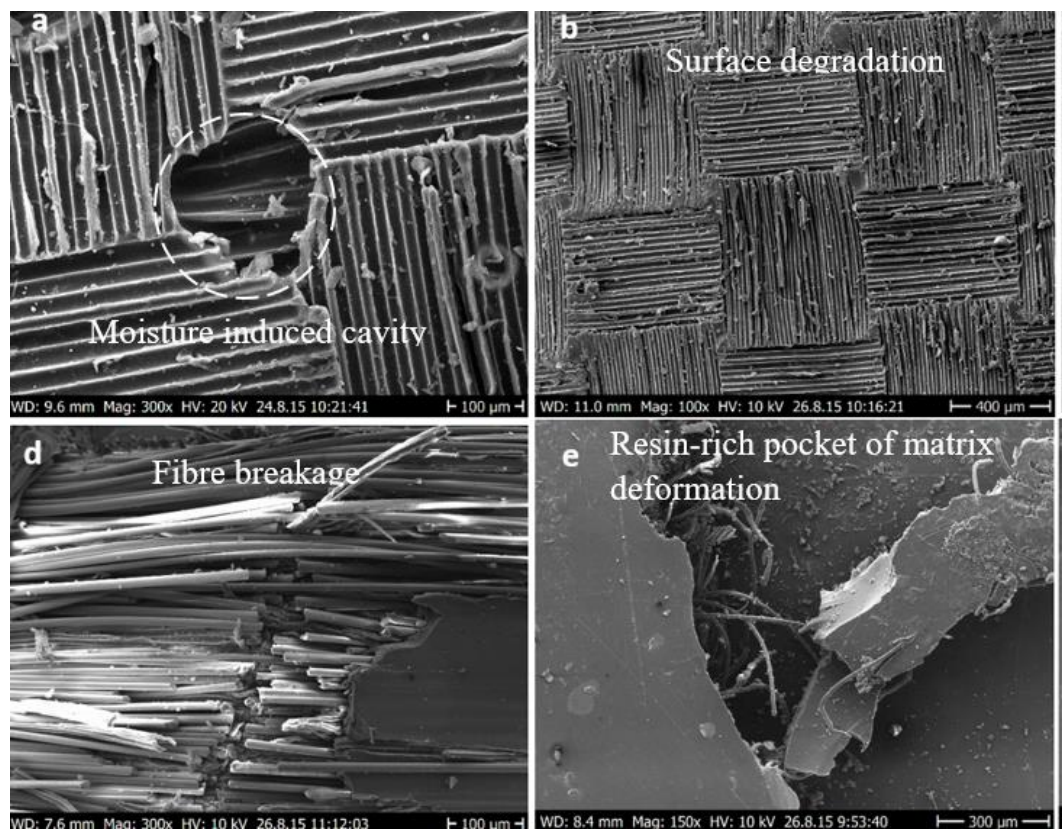
deformation
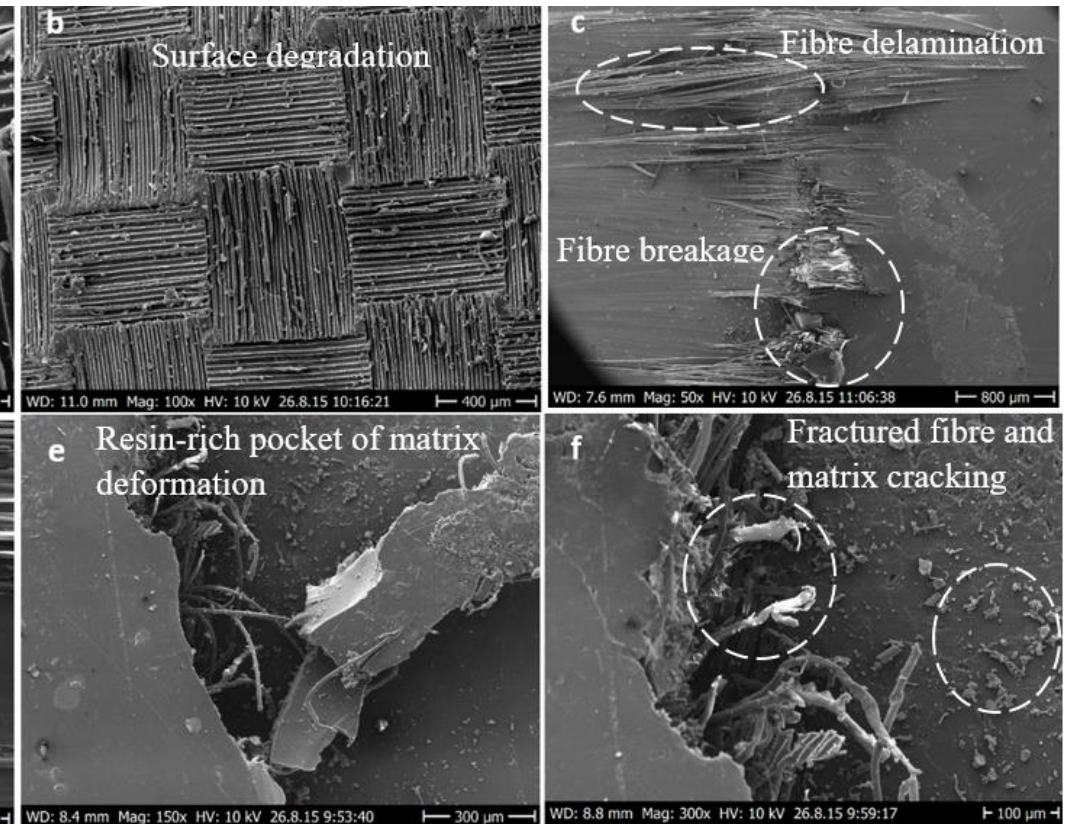

Fig. 13. SEM micrographs of the fracture surfaces for wet composites showing (a) Moisture induced cavity for FVE composite, (b) surface degradation due to moisture presence of FVE, (c) delamination of FBVEu, (d) fibre breakage of FBVEu, (e) resin rich pocket with matrix cracking of FBVEs, (f) fractured fibre and matrix cracking of FBVEs. 
Table 1 Chemical and structural composition of the natural (bast) fibres.

Table 2 Comparative values of physical and mechanical properties of flax and basalt fibres.

Table 3 Moisture uptake of FVE, FBVEu and FBVEs composite laminates immersed in de-ionised water at room temperature. 
Table 1 Chemical and structural composition of the natural (bast) fibres.

\begin{tabular}{|l|l|l|l|l|l|}
\hline Fibres & $\begin{array}{l}\text { Cellulose } \\
\text { crystallinity }(\%)\end{array}$ & $\begin{array}{l}\text { Cellulose } \\
\text { content }(\mathrm{wt} . \%)\end{array}$ & $\begin{array}{l}\text { Aspect ratio } \\
(1 / \mathrm{d})\end{array}$ & $\begin{array}{l}\text { Micro-fibril angl } \\
\left({ }^{0}\right)\end{array}$ & Source \\
\hline Flax & $50-90$ & $64-71$ & 1750 & $5-10$ & $(34)$ \\
\hline Hemp & $50-90$ & $70-74$ & 900 & $2-6$ & $(35)$ \\
\hline Jute & $50-80$ & $61-72$ & 100 & 8 & $(3)$ \\
\hline
\end{tabular}

Table 2 Comparative values of physical and mechanical properties of flax and basalt fibres.

\begin{tabular}{|l|l|l|l|l|l|l|}
\hline Fibre type & $\begin{array}{l}\text { Density } \\
\left(\mathrm{g} / \mathrm{cm}^{3}\right)\end{array}$ & $\begin{array}{l}\text { Young's } \\
\text { modulus } \\
(\mathrm{GPa})\end{array}$ & $\begin{array}{l}\text { Tensile } \\
\text { strength } \\
(\mathrm{MPa})\end{array}$ & $\begin{array}{l}\text { Elongation at } \\
\text { break } \\
(\%)\end{array}$ & $\begin{array}{l}\text { Specific } \\
\text { modulus } \\
\left(\mathrm{GPa} /\left(\mathrm{g} / \mathrm{cm}^{3}\right)\right)\end{array}$ & Reference \\
\hline Flax & 1.5 & 27.6 & $345-1035$ & $2.7-3.2$ & 18.4 & $(6,36)$ \\
\hline Basalt & 2.65 & $93-110$ & $\begin{array}{l}4150- \\
4800\end{array}$ & 3.1 & $35-41$ & $(37)$ \\
\hline E-glass & 2.50 & 70 & $\begin{array}{l}2000- \\
3500\end{array}$ & 2.5 & 28 & $(38)$ \\
\hline
\end{tabular}

* For comparison

Table 3 Moisture uptake of FVE, FBVEu and FBVEs composite laminates immersed in de-ionised water at room temperature.

\begin{tabular}{lllll}
\hline $\begin{array}{l}\text { Type of } \\
\text { sample }\end{array}$ & $\begin{array}{l}\text { Saturation } \\
\text { moisture } \\
M_{m}(\%)\end{array}$ & $\begin{array}{l}\text { Initial } \\
\text { plot }(k) \\
\text { versus } \mathrm{t}^{1 / 2}\end{array}$ & $\begin{array}{l}\text { slope of } \\
M(t)\end{array}$ & $\begin{array}{l}\text { Diffusion } \\
\text { coefficient, } \\
\text { x } 10^{-3}\left(\mathrm{~m}^{2} / \mathrm{s}\right)\end{array}$ \\
\hline FVE & 5.38 & 0.23 & $1.50776 \mathrm{E}-06$ \\
\hline FBVEs & 3.70 & 0.14 & $1.04705 \mathrm{E}-06$ \\
\hline FBVEu & 3.57 & 0.13 & $1.04705 \mathrm{E}-06$ \\
\hline
\end{tabular}

